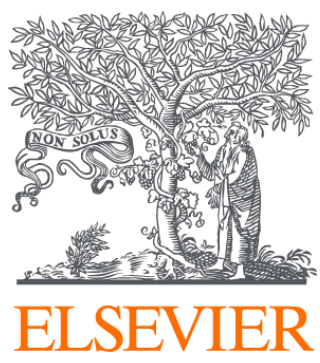

Since January 2020 Elsevier has created a COVID-19 resource centre with free information in English and Mandarin on the novel coronavirus COVID-

19. The COVID-19 resource centre is hosted on Elsevier Connect, the company's public news and information website.

Elsevier hereby grants permission to make all its COVID-19-related research that is available on the COVID-19 resource centre - including this research content - immediately available in PubMed Central and other publicly funded repositories, such as the WHO COVID database with rights for unrestricted research re-use and analyses in any form or by any means with acknowledgement of the original source. These permissions are granted for free by Elsevier for as long as the COVID-19 resource centre remains active. 
Original article

\title{
Design, synthesis, antiviral and cytostatic evaluation of novel isoxazolidine nucleotide analogues with a 1,2,3-triazole linker
}

\author{
Dorota G. Piotrowska ${ }^{\mathrm{a}, *}$, Jan Balzarini ${ }^{\mathrm{b}}$, Iwona E. Głowacka ${ }^{\text {a }}$ \\ a Bioorganic Chemistry Laboratory, Faculty of Pharmacy, Medical University of Łódź, 90-151 Lódź, Muszyńskiego 1, Poland \\ ${ }^{\mathrm{b}}$ Rega Institute for Medical Research, Katholieke Universiteit Leuven, Minderbroedersstraat 10, B-3000 Leuven, Belgium
}

\section{A R T I C L E I N F O}

\section{Article history:}

Received 7 April 2011

Received in revised form

10 November 2011

Accepted 10 November 2011

Available online 20 November 2011

\section{Keywords:}

Phosphonates

Isoxazolidines

Triazoles

Synthesis

Antiviral

Cytostatic

\begin{abstract}
A B S T R A C T
Azidation $\left(\mathrm{TMSN}_{3}, \mathrm{SnCl}_{4}\right)$ of a 9:1 mixture of trans- and cis-5-acetoxy-2-methylisoxazolidin-3-yl-3phosphonates at the anomeric carbon atom led to the formation of the equimolar mixture of cis- and trans-5-azido-2-methylisoxazolidin-3-yl-3-phosphonates, which were efficiently separated. The 1,3dipolar cycloaddition of pure trans- and cis-5-azidoisoxazolidin-3-yl-3-phosphonates with selected alkynes gave the respective nucleoside mimetics containing a 1,2,3-triazole linker. The (1,2,3-triazolyl) isoxazolidine phosphonates obtained herein were evaluated in vitro for activity against a variety of DNA and RNA viruses. None of the compounds were endowed with antiviral activity at subtoxic concentrations. Compounds $\mathbf{1 5 f}-\mathbf{j}$ and $\mathbf{1 6 f}-\mathbf{j}$ were cytostatic in the higher micromolar range.
\end{abstract}

(c) 2011 Elsevier Masson SAS. All rights reserved.

\section{Introduction}

An intensive search for drugs effective in chemotherapy of viral infections and/or various cancers has been under way for decades. The idea of structural modifications of nucleosides and nucleotides gained interest fairly early and appeared fruitful supplying a wide variety of marketed compounds such as ribavirin, zidovudine, adefovir and many others (Fig. 1). In general, the modifications included replacements of the phosphate $\mathrm{P}(\mathrm{O})-\mathrm{O}-\mathrm{C}$ bond for the non-hydrolysable phosphonate $\mathrm{P}(\mathrm{O})-\mathrm{C}$ linkage, a furanose ring for other heterocyclic or even acyclic fragments or natural nucleobases for unnatural, substituted heteroaromatic or even homoaromatic systems. Several functionalities have been tried as linkers and aliphatic chains as well as 3- to 6-membered aliphatic and aromatic homo- and heterocyclic systems exemplify a long list of examples [1-4].

Among commonly applied linkers a 1,2,3-triazole ring is of special interest since it is extremely easily to prepare by a 1,3dipolar cycloaddition and biological activity of many 1,2,3-triazole derivatives has been recognised (Fig. 2). The idea of retaining the natural nucleobases with simultaneous introduction of the

\footnotetext{
* Corresponding author. Tel.: +48 4267792 35; fax: +48 426788398.

E-mail address: dorota.piotrowska@umed.lodz.pl (D.G. Piotrowska).
}

functionalised 1,2,3-triazole unit into a furanose ring led to compounds 1 and $\mathbf{2}$ which showed an antiviral activity [5,6]. On the other hand $2^{\prime}, 3^{\prime}$-diethanethio-2', $3^{\prime}, 5^{\prime}$-trideoxy-5'-triazolonucleosides 3 displayed antitumour activity [7]. Recently, Kim et al. designed novel 1,2,3-triazole-appended C5-modified nucleosides 4 and their anticancer activity was demonstrated [8,9]. Various acyclonucleosides [10,11] and acyclonucleoside phosphonates [12] containing a 1,2,3-triazole unit were obtained from $N$-propargyl nucleobases and their antiviral activity was evaluated. Among them, pyrimidine- and purine-containing derivatives 5 and $\mathbf{6}$ appeared to be the most potent so far and exhibited anti-HCV activity ( $\mathrm{IC}_{50}$ values of $16 \mu \mathrm{M}$ ) without any cytotoxicity at a concentration up to $100 \mu \mathrm{M}$. On the basis of a similar idea, novel 1,2,3-triazole nucleosides 7 linked to DNA nucleobases as a recognition element have been synthesised and their antiviral activity was evaluated [13].

Recently, we succeeded in the synthesis of $\mathrm{N}$-substituted $\mathrm{C}$ phosphorylated nitrone 8 [14] and its application in the 1,3-dipolar cycloaddition with vinyl acetate was described [15]. Furthermore, the usefulness of C5-acetoxyisoxazolidines $\mathbf{9}$ as precursors in the synthesis of isoxazolidine nucleoside analogues $\mathbf{1 0}$ has recently been demonstrated (Scheme 1) [15,16].

In continuation of these efforts, a novel class of 1,2,3-triazolecontaining isoxazolidine nucleosides $\mathbf{1 1}$ (Scheme 2) was designed. Although glycosyl as well as furanosyl azides have commonly 


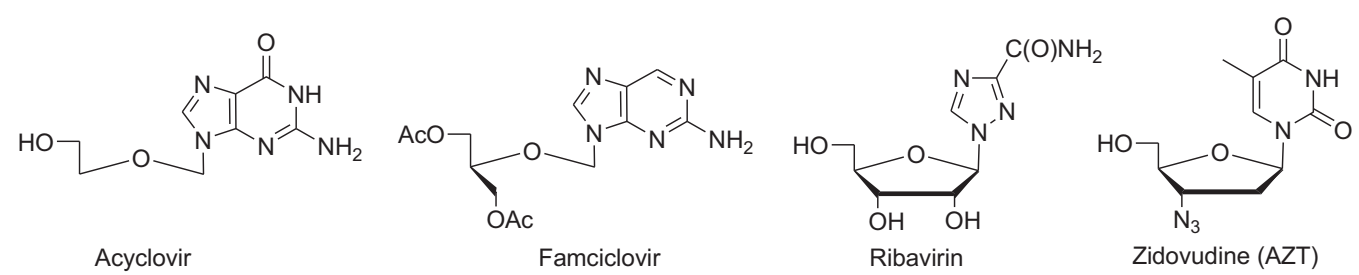

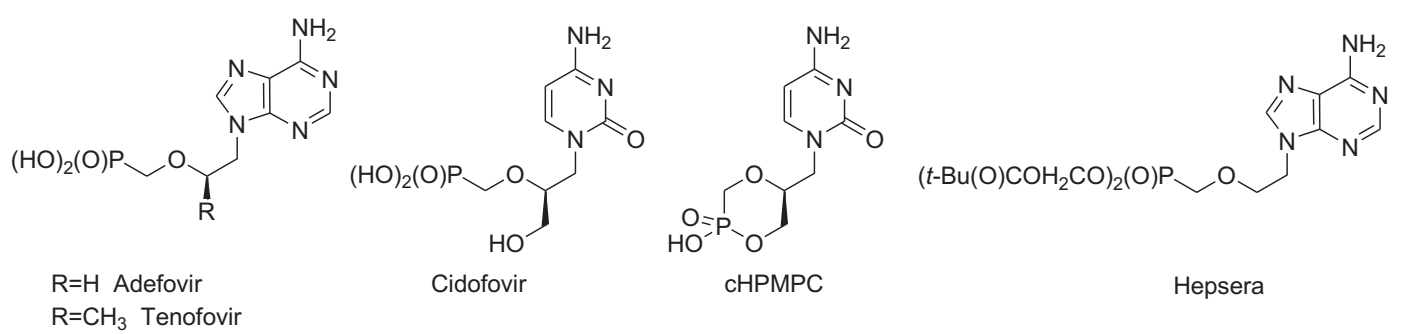

Fig. 1. Examples of marketed nucleoside and nucleotide analogues.

been used in a direct synthesis of substituted 1,2,3-triazoles $[13,17-20]$, to the best of our knowledge isoxazolidine analogues of 1-azidofuranose remain unknown. Herein, we wish to report the efficient synthesis of 5-azidoisoxazolidines $\mathbf{1 2}$ from 5acetoxyisoxazolidines $\mathbf{9}$ and further transformation of the azides 12 into the respective nucleoside mimetics $\mathbf{1 1}$. The aim of this study was the preparation of a small library of nucleotide analogues $\mathbf{1 1}$ which was based on the idea of replacing of a furanose ring by an isoxazolidine system and introduction of a 1,2,3-triazole linker between isoxazolidine and the respective purine or pyrimidine nucleobase or other aromatic function as a nucleobase replacer (Scheme 2).

\section{Results and discussion}

\subsection{Chemistry}

A 9:1 mixture of trans- and cis-5-acetoxyisoxazolidines $\mathbf{9 a}$ and 9b was obtained from $N$-methyl- $C$-phosphorylated nitrone $\mathbf{8}$ and vinyl acetate as previously described [21]. This mixture was immediately treated with $\mathrm{TMSN}_{3}$ in the presence of $\mathrm{SnCl}_{4}$ as a catalyst to give 5-azidoisoxazolidines $\mathbf{1 2}$ and $\mathbf{1 3}$ in a $\sim 1$ ratio (Scheme 3) [22]. They were cleanly separated on a silica gel column into the less polar diastereoisomer 13 (50\%) and more polar 12 (46\%).

Since almost an equimolar mixture of both anomeric azides 12 and 13 was detected in a crude product, the replacement of the acetoxy group at $\mathrm{C5}$ with an azide function occurred via the formation of the respective oxonium intermediate. Under these circumstances the nucleophile can attack both faces of the isoxazolidinium ion to form the azides $\mathbf{1 2}$ and $\mathbf{1 3}$ as a ca. 1:1 anomeric mixture.

The relative configurations in the diastereoisomeric isoxazolidines 12 and 13 were established based on ${ }^{1} \mathrm{H}$ and ${ }^{13} \mathrm{C}$ NMR spectroscopic data $[23,24]$. Analysis of vicinal coupling constants extracted from the spectra of the isomer $\mathbf{1 2}$ $\left[J\left(\mathrm{H}_{3}-\mathrm{H}_{4 \alpha}\right)=6.8 \mathrm{~Hz}, \quad J\left(\mathrm{H}_{3}-\mathrm{H}_{4 \beta}\right)=10.8 \mathrm{~Hz}, \quad J\left(\mathrm{H}_{4 \alpha}-\mathrm{P}\right)=4.0 \mathrm{~Hz}\right.$, $J\left(\mathrm{H}_{4 \beta}-\mathrm{P}\right)=17.0 \mathrm{~Hz}, J\left(\mathrm{H}_{4 \alpha}-\mathrm{H}_{5}\right)=0.8 \mathrm{~Hz}, J\left(\mathrm{H}_{4 \beta}-\mathrm{H}_{5}\right)=5.3 \mathrm{~Hz}$ and $J(C C C P)=10.3 \mathrm{~Hz}]$ shows that the isoxazolidine ring exists in the single ${ }^{4} E$ conformation. In this conformation the $\mathrm{P}(\mathrm{O})(\mathrm{OEt})_{2}$ and

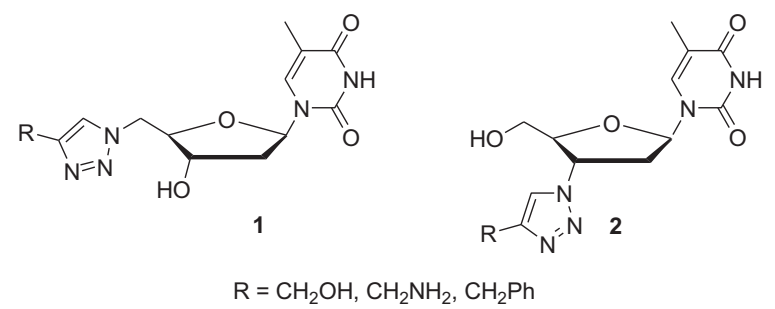

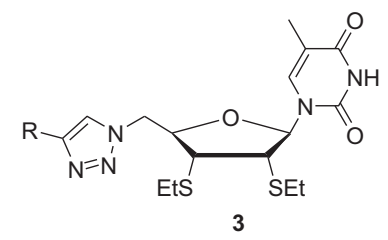

$\mathrm{R}=\mathrm{C}_{6} \mathrm{H}_{5}, 4-\mathrm{F}-\mathrm{C}_{6} \mathrm{H}_{4}, 4-\mathrm{Me}^{-} \mathrm{C}_{6} \mathrm{H}_{4}$, $4-\mathrm{Me}_{6} \mathrm{C}_{6} \mathrm{H}_{4}, 2-\mathrm{CF}_{3}-\mathrm{C}_{6} \mathrm{H}_{4}$
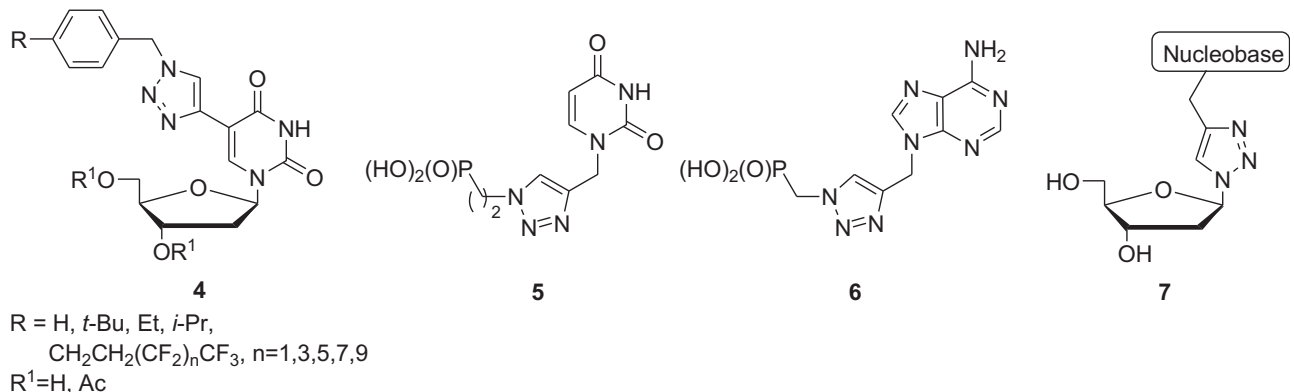
$\mathrm{R}^{1}=\mathrm{H}, \mathrm{Ac}$

Fig. 2. Biologically active nucleoside mimetics having functionalised 1,2,3-triazole unit. 


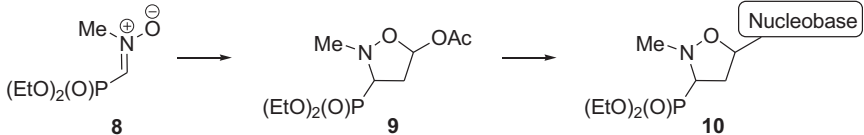

Scheme 1. Transformation of the $C$-phosphorylated nitrone $\mathbf{8}$ into isoxazolidine nucleoside analogues $\mathbf{1 0 .}$

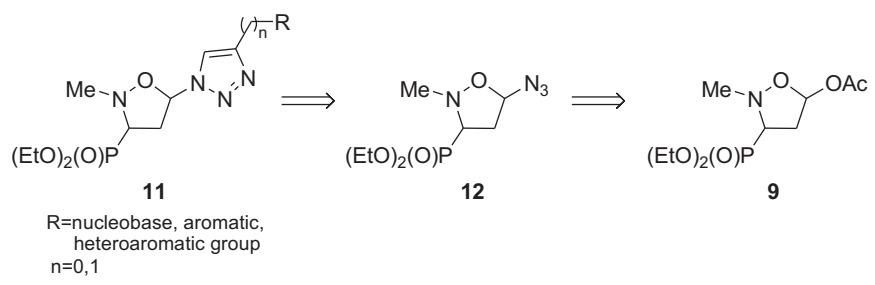

Scheme 2. Retrosynthesis of nucleoside mimetics $\mathbf{1 1}$.

azido groups occupy the pseudoequatorial and pseudoaxial positions, respectively (Fig. 3) and thus reveal the trans relationship of $\mathrm{H}_{3}$ and $\mathrm{H}_{5}$. On the other hand, from the NMR spectra of the isoxazolidine $\mathbf{1 3}$ the following couplings were calculated: $J\left(\mathrm{H}_{3}-\mathrm{H}_{4 \alpha}\right)=9.3 \mathrm{~Hz}, \quad J\left(\mathrm{H}_{3}-\mathrm{H}_{4 \beta}\right)=9.1 \mathrm{~Hz}, \quad J\left(\mathrm{H}_{4 \alpha}-\mathrm{P}\right)=4.8 \mathrm{~Hz}$, $J\left(\mathrm{H}_{4 \beta}-\mathrm{P}\right)=17.0 \mathrm{~Hz}, J\left(\mathrm{H}_{4 \alpha}-\mathrm{H}_{5}\right)=7.5 \mathrm{~Hz}, J\left(\mathrm{H}_{4 \beta}-\mathrm{H}_{5}\right)=2.4 \mathrm{~Hz}$ and $J(C C C P)=10.3 \mathrm{~Hz}$. On the basis of these values, a preferred $E_{3}$ conformation having the diethoxyphosphoryl and azido groups in equatorial and pseudoequatorial positions was established (Fig. 3). At the same time, the cis relationship of the substituents at $\mathrm{C} 3$ and $\mathrm{C} 5$ in $\mathbf{1 3}$ was unambiguously proved.

Next the 1,3-dipolar cycloadditions of the 5-azidoisoxazolidines 12 and 13 with propargylated nucleobases and selected ethynyl aryls were examined (Scheme 4, Table 1). Because we were interested in the formation of single regioisomers of $C 4^{\prime}$-substituted 1,2,3-triazoles, all reactions were carried out with equimolar amounts of the respective dipolarophiles 14 using $\mathrm{Cu}(\mathrm{I})$ as a catalyst, according to the procedure described by Sharpless $[25,26]$. Indeed, 5-azidoisoxazolidin-3-yl-3-phosphonate trans-12 was cleanly transformed into C4'-substituted 1,2,3-triazoles trans-15 in good to excellent yields, whereas from cis-13 and the respective alkynes 14, isoxazolidines cis-16 were produced exclusively. In all cycloadditions no epimerization at $\mathrm{C} 5$ in the isoxazolidine ring was observed.

Additional evidence supporting our configurational assignments in the azidoisoxazolidines 12 and 13 comes from the comparison of the ${ }^{1} \mathrm{H}$ and ${ }^{13} \mathrm{C}$ NMR spectroscopic data of the respective (1,2,3-triazol-1-yl)isoxazolidines $\mathbf{1 5}$ and $\mathbf{1 6}$. Based on the vicinal couplings $\left[J\left(\mathrm{H}_{3}-\mathrm{H}_{4 \alpha}\right)=6.8-6.9 \mathrm{~Hz}, \quad J\left(\mathrm{H}_{3}-\mathrm{H}_{4 \beta}\right)=\right.$ $10.5-11.1 \mathrm{~Hz}, \quad J\left(\mathrm{H}_{4 \alpha}-\mathrm{P}\right)=4.5-6.8 \mathrm{~Hz}, \quad J\left(\mathrm{H}_{4 \beta}-\mathrm{P}\right)=16.8-71.7 \mathrm{~Hz}$, $J\left(\mathrm{H}_{4 \alpha}-\mathrm{H}_{5}\right)=1.2-1.8 \mathrm{~Hz}, \quad J\left(\mathrm{H}_{4 \beta}-\mathrm{H}_{5}\right)=6.6-6.9 \mathrm{~Hz}$ and $J(\mathrm{CCCP})=$ 9.4-10.5 Hz] observed in the ${ }^{1} \mathrm{H}$ and ${ }^{13} \mathrm{C}$ NMR spectra of the isoxazolidines 15 it was concluded that they exist in the ${ }^{4} E$ conformation, the same as observed for the azidoisoxazolidine 12 (Fig. 4). On the other hand, the preferred $E_{3}$ conformation for all $(1,2,3-$ triazol-1-yl)isoxazolidines $\mathbf{1 6}$ was established based on the vicinal coupling constants derived from their NMR spectra $\left[J\left(\mathrm{H}_{3}-\mathrm{H}_{4 \alpha}\right)=\right.$ 9.0-9.9 Hz, $J\left(\mathrm{H}_{3}-\mathrm{H}_{4 \beta}\right)=8.1-9.0 \mathrm{~Hz}, \quad J\left(\mathrm{H}_{4 \alpha}-\mathrm{P}\right)=5.4-6.0 \mathrm{~Hz}$,
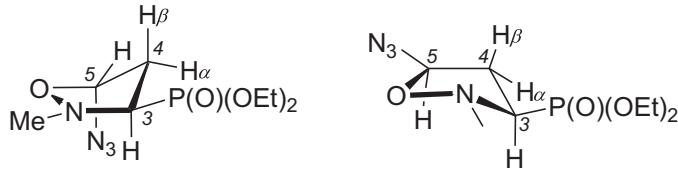

Fig. 3. The preferred conformations of 5-azidoisoxazolidines $\mathbf{1 2}$ (left) and $\mathbf{1 3}$ (right).

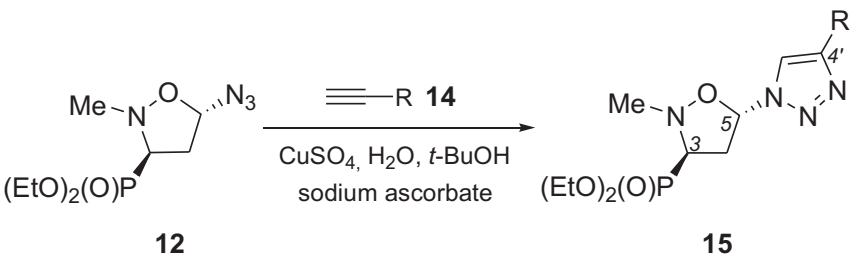

Scheme 4. 1,3-Dipolar cycloadditions of the 5-azidoisoxazolidines 12 with propargylated nucleobases and selected ethynyl aryls.

$J\left(\mathrm{H}_{4 \beta}-\mathrm{P}\right)=17.2-18.0 \mathrm{~Hz}, \quad J\left(\mathrm{H}_{4 \alpha}-\mathrm{H}_{5}\right)=7.8-7.9 \mathrm{~Hz}, \quad J\left(\mathrm{H}_{4 \beta}-\mathrm{H}_{5}\right)=$ $2.0-2.4 \mathrm{~Hz}$ and $J(\mathrm{CCCP})=8.6-9.7 \mathrm{~Hz}$ (Fig. 4).

\subsection{Antiviral and cytostatic evaluation}

All (1,2,3-triazol-1-yl)isoxazolidines trans-15 and cis-16 were evaluated for inhibitory activity against a wide variety of DNA and RNA viruses, using the following cell-based assays: (a) human embryonic lung (HEL) cells: herpes simplex virus-1 (KOS), herpes simplex virus-2 $(G)$, herpes simplex virus-1 (TK $\left.{ }^{-} \mathrm{KOS} \mathrm{ACV}^{\mathrm{r}}\right)$, vaccinia virus and vesicular stomatitis virus, cytomegalovirus (AD169 strain and Davis strain) and varicella-zoster virus ( $\mathrm{TK}^{+} \mathrm{VZV}$ strain Oka, and $\mathrm{TK}^{-}$VZV strain 07/1); (b) Vero cell cultures: parainfluenza-3 virus, reovirus-1, Sindbis virus, Coxsackie virus B4, Punta Toro virus; (c) HeLa cell cultures: vesicular stomatitis virus, Coxsackie virus B4 and respiratory syncytial virus; (d) MDCK cell cultures: influenza A virus (H1N1 and H3N2) and influenza B virus; (e) CrFK cell cultures: feline herpes virus (FHV) and feline corona virus (FIPV) and (f) CEM cell cultures: human immunodeficiency virus type 1 (HIV-1) and HIV-2. Ganciclovir, cidofovir, acyclovir, brivudin, (S)-9-(2,3-dihydroxypropyl)adenine [(S)-DHPA], oseltamivir and ribavirin were used as the reference compounds. The antiviral activity was expressed as the $\mathrm{EC}_{50}$ : the compound concentration required to reduce virus plaque formation (VZV) by $50 \%$ or to reduce virus-induced cytopathogenicity by $50 \%$ (other viruses). Unfortunately, no inhibitory activity against any virus was detected for the evaluated compounds at $250 \mu \mathrm{M}$.

The cytotoxicity of the tested compounds towards the uninfected host cells was defined as the minimum compound concentration (MCC) that caused a microscopically detectable alteration of normal cell morphology. The $50 \%$ cytostatic concentration $\left(\mathrm{CC}_{50}\right)$, causing a 50\% decrease in cell proliferation was determined against murine leukaemia L1210, human lymphocyte CEM, human cervix carcinoma HeLa and human lung fibroblast HEL cells. None of the tested compounds affected cell morphology of HEL, HeLa, Vero, MDCK and CrFK cells at concentrations up to $100 \mu \mathrm{M}$. However, several compounds (trans-15f-j and cis-16f-j) were able to inhibit

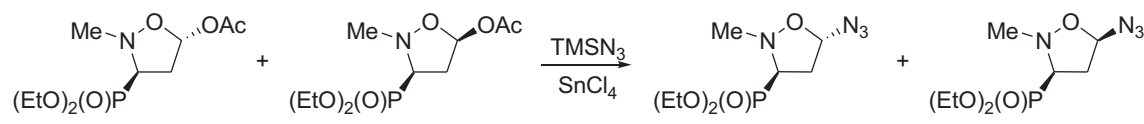

9a

$9 b$

12

13

Scheme 3. Synthesis of 5-azidoisoxazolidines $\mathbf{1 2}$ and $\mathbf{1 3}$ 
Table 1

Isoxazolidines $\mathbf{1 5}$ and $\mathbf{1 6}$ produced via Scheme 4

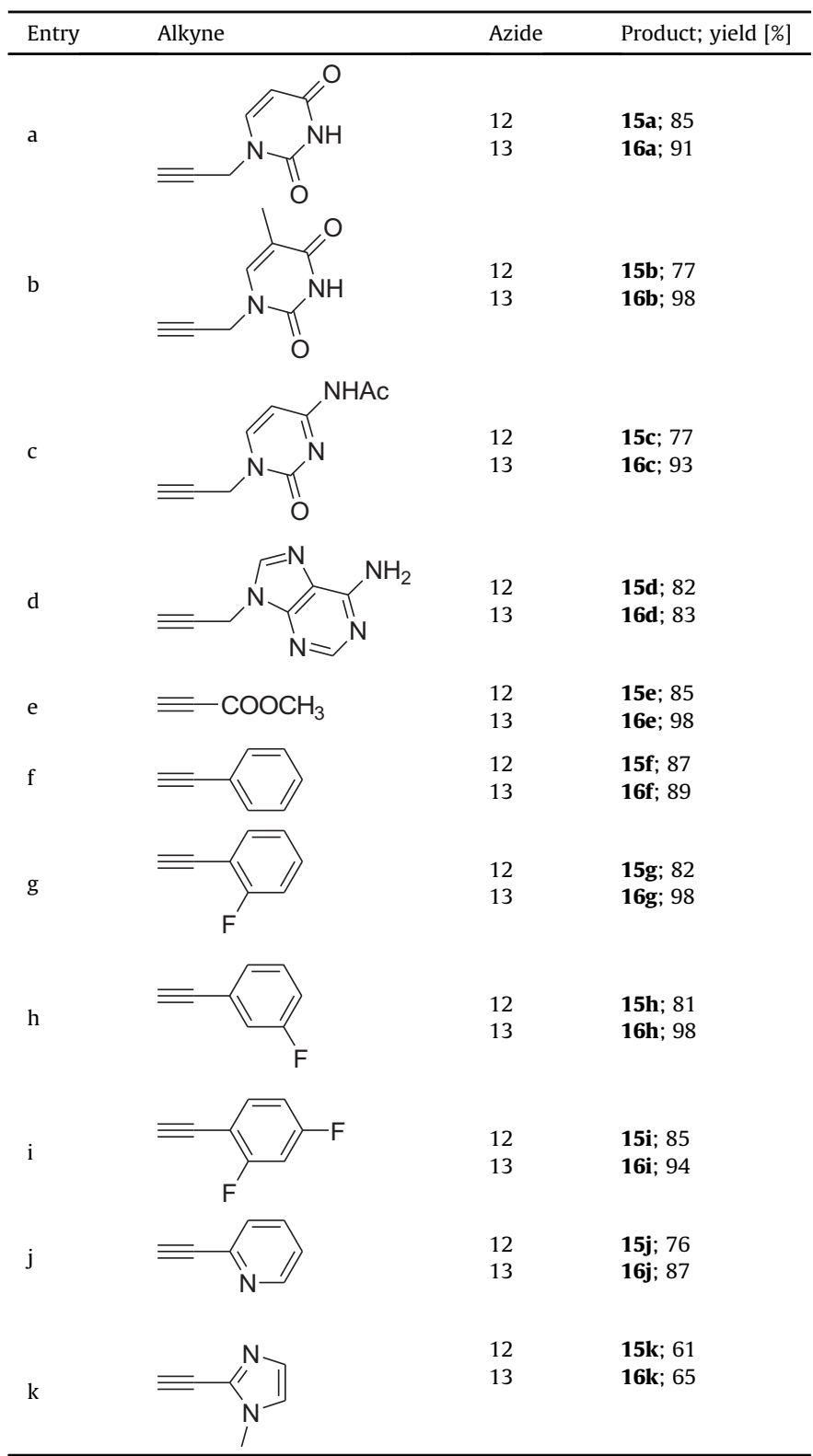

cell proliferation by $50 \%\left(\mathrm{CC}_{50}\right)$ at concentrations ranging from 40 to $78 \mu \mathrm{M}$ for HEL cells, and from 120 to $250 \mu \mathrm{M}$ for L1210, CEM and HeLa cells (Table 2).

Active as cell proliferation inhibitors isomeric isoxazolidines 15/ $\mathbf{1 6 f}-\mathbf{j}$ exhibit several common structural features such as a sixmembered aromatic ring (benzene or pyridine) and substitution
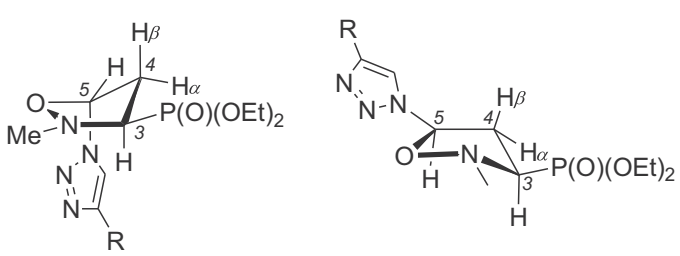

Fig. 4. The preferred conformations of (1,2,3-triazol-1-yl)isoxazolidines $\mathbf{1 5}$ (left) and 16 (right).
Table 2

Cytostatic activity of compounds $\mathbf{1 5 a}-\mathbf{k}$ and $\mathbf{1 6} \mathbf{a}-\mathbf{k}$.

\begin{tabular}{|c|c|c|c|c|}
\hline \multirow[t]{2}{*}{ Compound } & \multicolumn{4}{|c|}{$\mathrm{CC}_{50}^{\mathrm{a}}(\mu \mathrm{M})$} \\
\hline & L1210 & CEM & HeLa & HEL \\
\hline $15 a$ & $>250$ & $>250$ & $\geq 250$ & $>100$ \\
\hline $15 b$ & $\geq 250$ & $>250$ & $>250$ & $>100$ \\
\hline $15 c$ & $\geq 250$ & $>250$ & $>250$ & $>100$ \\
\hline 15d & 140 & $>250$ & $>250$ & $>100$ \\
\hline $15 e$ & 191 & $>250$ & $>250$ & $>100$ \\
\hline $15 f$ & $>250$ & $>250$ & $>250$ & 40 \\
\hline $15 \mathrm{~g}$ & 120 & $>250$ & 202 & 73 \\
\hline $15 h$ & $\geq 250$ & $>250$ & $\geq 250$ & 40 \\
\hline $15 i$ & 131 & $\geq 250$ & 162 & 59 \\
\hline $15 j$ & $\geq 250$ & $>250$ & $>250$ & 62 \\
\hline $15 k$ & $\geq 250$ & $>250$ & $>250$ & $>100$ \\
\hline $16 a$ & 235 & $>250$ & $>250$ & $>100$ \\
\hline $16 b$ & 280 & $>250$ & $>250$ & $>100$ \\
\hline $16 c$ & $>250$ & $>250$ & $>250$ & $>100$ \\
\hline $16 d$ & 147 & $>250$ & $\geq 250$ & $>100$ \\
\hline $16 e$ & 166 & $>250$ & $>250$ & $>100$ \\
\hline $16 f$ & 172 & $>250$ & $>250$ & 54 \\
\hline $16 \mathrm{~g}$ & 122 & $>250$ & 247 & 41 \\
\hline $16 h$ & 104 & $>250$ & 212 & 43 \\
\hline $16 i$ & 124 & $\geq 250$ & 135 & 42 \\
\hline $16 j$ & 206 & $>250$ & $>250$ & 78 \\
\hline $16 k$ & $\geq 250$ & $>250$ & $>250$ & $>100$ \\
\hline
\end{tabular}

a $50 \%$ Inhibitory concentration or compound concentration required to inhibit cell proliferation by $50 \%$.

with fluorine. The aromatic fragments of these compounds fulfil the requirements to be considered as "nonpolar nucleoside isosteres" [27].

\section{Conclusions}

Azidation of a 9:1 mixture of trans- and cis-5-acetoxy-2methylisoxazolidin-3-yl-3-phosphonates with trimethylsilyl azide in the presence of $\mathrm{SnCl}_{4}$ gave an easily separable $1: 1$ mixture of diethyl 5-azido-2-methylisoxazolidin-3-yl-3-phosphonates trans12 and cis-13. A series of 1,2,3-triazole-containing isoxazolidin-3yl-3-phosphonates was obtained in good to excellent yields from azides trans-12 and cis-13 via 1,3-dipolar cycloaddition with the respective propargylated nucleobases and ethynyl aryls.

The relative configuration in the 5-azidoisoxazolidines trans-12 and cis-13 as well as the 1,2,3-triazolyl cycloadducts trans-15 and cis-16 was established based on the conformational analysis using vicinal coupling constants extracted from ${ }^{1} \mathrm{H}$ and ${ }^{13} \mathrm{C}$ NMR spectra.

All synthesised trans- and cis-(1,2,3-triazolyl)isoxazolidinephosphonates trans-15 and cis-16 were evaluated against a broadspectrum of viruses but found not active at $250 \mu \mathrm{M}$. The unsubstituted and fluoro-substituted phenyl derivatives proved slightly cytostatic (middle to higher micromolar range: $40-250 \mu \mathrm{M})$.

\section{Experimental section}

\subsection{Chemistry}

The ${ }^{1} \mathrm{H}$ NMR spectra were taken in $\mathrm{CDCl}_{3}$ or $\mathrm{C}_{6} \mathrm{D}_{6}$ on the Varian Mercury-300 spectrometer with TMS as an internal standard. The ${ }^{13} \mathrm{C}$ NMR spectra were recorded for $\mathrm{CDCl}_{3}$ solutions on a Varian Mercury-300 machine at $75.5 \mathrm{MHz}$. The ${ }^{31} \mathrm{P}$ NMR spectra were taken in $\mathrm{CDCl}_{3}$ or $\mathrm{C}_{6} \mathrm{D}_{6}$ on Varian Mercury-300 at $121.5 \mathrm{MHz}$.

IR spectra were measured on an Infinity MI-60 FT-IR spectrometer. Melting points were determined on a Boetius apparatus and are uncorrected. Elemental analyses were performed by the 
Microanalytical Laboratory of this Faculty on Perkin-Elmer PE 2400 CHNS analyser.

The following adsorbents were used: column chromatography, Merck silica gel 60 (70-230 mesh); analytical TLC, Merck TLC plastic sheets silica gel $60 \mathrm{~F}_{254}$.

Starting Materials. All solvents were dried according to the literature methods. The nitrone $\mathbf{8}$ and isoxazolidines $\mathbf{9 a}$ and $\mathbf{9 b}$ were previously reported [21].

\subsubsection{Synthesis of 5-azidoisoxazolidines 12 and 13}

To a solution of a 9:1 mixture of 5-acetoxyisoxazolidines $\mathbf{1 0}$ and 11 (3.384 g, $12.03 \mathrm{mmol})$ in dry methylene chloride $(40 \mathrm{~mL})$ trimethylsilyl azide $(3.97 \mathrm{~mL}, 30.08 \mathrm{mmol})$ was added at $0{ }^{\circ} \mathrm{C}$ under argon followed by $\mathrm{SnCl}_{4}(0.704 \mathrm{~mL}, 6.02 \mathrm{mmol})$. The reaction mixture was stirred at this temperature for $12 \mathrm{~h}$ and then saturated aqueous $\mathrm{NaHCO}_{3}(70 \mathrm{~mL})$ was added at $0{ }^{\circ} \mathrm{C}$. After stirring for $30 \mathrm{~min}$ at this temperature organic phase was separated, and an aqueous layer was extracted with methylene chloride $(4 \times 20 \mathrm{~mL})$. The combined organic layers were washed with saturated aqueous $\mathrm{NaHCO}_{3}(2 \times 20 \mathrm{~mL})$, dried over $\mathrm{MgSO}_{4}$, filtered and solvent was removed under reduced pressure. Purification on a silica gel column with toluene:isopropanol (200:1 and then 100:1, v/v) gave azidoisoxazolidine 13 (1.587 g, 50\%) and azidoisoxazolidine 12 (1.468 $\mathrm{g}, 46 \%)$, both as colourless oils.

4.1.1.1. Diethyl 5-azido-2-methylisoxazolidin-3-yl-3-phosphonate 12. IR (film, $\mathrm{cm}^{-1}$ ) $\nu_{\max }: 3473,2962,2114,1443,1260,1240,1100$, 1054, 1026, 964, 800; ${ }^{1} \mathrm{H}$ NMR $\left(300 \mathrm{MHz}, \mathrm{CDCl}_{3}\right) \delta: 1.35(\mathrm{t}, 6 \mathrm{H}$, $J=6.9 \mathrm{~Hz}, 2 \times \mathrm{POCH}_{2} \mathrm{CH}_{3}$ ), 2.47 (dddd, $1 \mathrm{H}, J=12.6,6.8,4.0,0.8 \mathrm{~Hz}$, HbC4), 2.63 (dddd, $1 \mathrm{H}, J=17.0,12.6,10.8,5.3 \mathrm{~Hz}, \mathrm{HaC} 4), 3.04$ (d, $3 \mathrm{H}$, $J=1.0 \mathrm{~Hz}, \mathrm{CH}_{3}-\mathrm{N}$ ), 3.27 (ddd, $1 \mathrm{H}, J=10.8 \mathrm{~Hz}, 6.8,2.4 \mathrm{~Hz}, H C 3$ ), $4.15-4.30\left(\mathrm{~m}, 4 \mathrm{H}, 2 \times \mathrm{POCH}_{2} \mathrm{CH}_{3}\right), 5.58(\mathrm{dd}, 1 \mathrm{H}, J=5.3,0.8 \mathrm{~Hz}, \mathrm{HC} 5)$; ${ }^{13} \mathrm{C}$ NMR $\left(75.5 \mathrm{MHz}, \mathrm{CDCl}_{3}\right) \delta$ : $16.6(\mathrm{~d}, J=6.2 \mathrm{~Hz}), 40.2(\mathrm{~d}$, $\left.{ }^{2} J_{\mathrm{PCC}}=1.9 \mathrm{~Hz}, \quad \mathrm{C} 4\right), \quad 49.5 \quad\left(\mathrm{~d}, \quad J=6.9 \mathrm{~Hz}, \quad \mathrm{CH}_{3}-\mathrm{N}\right), \quad 62.2 \quad(\mathrm{~d}$, $\left.{ }^{1} J_{\mathrm{PC}}=175.2 \mathrm{~Hz}, \mathrm{C} 3\right), 62.8(\mathrm{~d}, J=7.0 \mathrm{~Hz}, \mathrm{C}-\mathrm{O}-\mathrm{P}), 63.4(\mathrm{~d}, J=6.9 \mathrm{~Hz}$, $\mathrm{C}-\mathrm{O}-\mathrm{P}), 89.8\left(\mathrm{~d},{ }^{3}{ }_{\mathrm{PCCC}}=10.3 \mathrm{~Hz}, \mathrm{C} 5\right) ;{ }^{31} \mathrm{P} \mathrm{NMR}\left(121.5 \mathrm{MHz}, \mathrm{CDCl}_{3}\right)$ $\delta$ : 22.39. Anal. Calcd for $\mathrm{C}_{8} \mathrm{H}_{17} \mathrm{~N}_{4} \mathrm{O}_{4} \mathrm{P}: \mathrm{C}, 36.37 ; \mathrm{H}, 6.49 ; \mathrm{N}, 21.20$. Found: C, 36.25; H, 6.59; N, 20.98 .

4.1.1.2. Diethyl 5-azido-2-methylisoxazolidin-3-yl-3-phosphonate 13. IR (film, $\mathrm{cm}^{-1}$ ) $\nu_{\max }: 3580,2981,1442,1257,1053,1027,968$; ${ }^{1} \mathrm{H}$ NMR (300 MHz, $\left.\mathrm{CDCl}_{3}\right) \delta: 1.36\left(\mathrm{t}, 3 \mathrm{H}, J=7.1 \mathrm{~Hz}, \mathrm{POCH}_{2} \mathrm{CH}_{3}\right), 1.38$ $\left(\mathrm{t}, 3 \mathrm{H}, J=7.1 \mathrm{~Hz}, \mathrm{POCH}_{2} \mathrm{CH}_{3}\right), 2.40-2.60(\mathrm{~m}, 1 \mathrm{H}, \mathrm{HbC} 4), 2.80-2.90$ $(\mathrm{m}, 1 \mathrm{H}, \mathrm{HaC} 4), 2.85-2.98(\mathrm{~m}, 1 \mathrm{H}, \mathrm{HC} 3), 2.96\left(\mathrm{~s}, 3 \mathrm{H}, \mathrm{CH}_{3}-\mathrm{N}\right)$, $4.15-4.30\left(\mathrm{~m}, 4 \mathrm{H}, 2 \times \mathrm{POCH}_{2} \mathrm{CH}_{3}\right), 5.41$ (very br d, $\left.1 \mathrm{H}, \mathrm{HC} 5\right) ;{ }^{1} \mathrm{H}$ NMR $\left(300 \mathrm{MHz}, \mathrm{C}_{6} \mathrm{D}_{6}\right) \delta: 0.99\left(\mathrm{t}, 3 \mathrm{H}, J=7.1 \mathrm{~Hz}, \mathrm{POCH}_{2} \mathrm{CH}_{3}\right), 1.11(\mathrm{t}, 3 \mathrm{H}$, $J=7.1 \mathrm{~Hz}, \mathrm{POCH}_{2} \mathrm{CH}_{3}$ ), 2.16 (dddd, $1 \mathrm{H}, J=12.8,9.3,7.5,4.8 \mathrm{~Hz}$, HbC4), 2.42 (dddd, $1 \mathrm{H}, J=17.0,12.8,9.1,2.4 \mathrm{~Hz}, \mathrm{HaC} 4$ ), 2.55 (ddd, $1 \mathrm{H}, J=9.3,9.1,2.0 \mathrm{~Hz}, \mathrm{HC} 3), 2.94\left(\mathrm{~d}, 3 \mathrm{H}, J=1.2 \mathrm{~Hz}, \mathrm{CH}_{3}-\mathrm{N}\right)$, 3.80-3.98 (m, $\left.2 \mathrm{H}, \mathrm{POCH}_{2} \mathrm{CH}_{3}\right), 4.00-4.23\left(\mathrm{~m}, 2 \mathrm{H}, \mathrm{POCH}_{2} \mathrm{CH}_{3}\right), 4.64$ $(\mathrm{dd}, 1 \mathrm{H}, J=7.5,2.4 \mathrm{~Hz}, \mathrm{HC} 5) ;{ }^{13} \mathrm{C}$ NMR $\left(75.5 \mathrm{MHz}, \mathrm{CDCl}_{3}\right) \delta: 16.6(\mathrm{~d}$, $J=6.4 \mathrm{~Hz}), 16.7(\mathrm{~d}, J=6.0 \mathrm{~Hz}), 40.5\left(\mathrm{~d},{ }^{2} J_{\mathrm{PCC}}=2.8 \mathrm{~Hz}, \mathrm{C} 4\right), 45.8(\mathrm{~d}$, $\left.J=2.3 \mathrm{~Hz}, \mathrm{CH}_{3}-\mathrm{N}\right), 62.6(\mathrm{~d}, J=6.5 \mathrm{~Hz}, \mathrm{C}-\mathrm{O}-\mathrm{P}), 63.7$ (d, $J=6.5 \mathrm{~Hz}$, C-O-P), 63.9 (d, $\left.J_{\mathrm{PC}}=164.8 \mathrm{~Hz}, \mathrm{C} 3\right), 88.0\left(\mathrm{~d},{ }^{3} \mathrm{JPCC}_{\mathrm{PCC}}=10.3 \mathrm{~Hz}, \mathrm{C} 5\right)$; ${ }^{31} \mathrm{P}$ NMR (121.5 MHz, $\left.\mathrm{C}_{6} \mathrm{D}_{6}\right) \delta: 21.03 ;{ }^{31} \mathrm{P}$ NMR $\left(121.5 \mathrm{MHz}, \mathrm{CDCl}_{3}\right) \delta$ : 21.38. Anal. Calcd for $\mathrm{C}_{8} \mathrm{H}_{17} \mathrm{~N}_{4} \mathrm{O}_{4} \mathrm{P}: \mathrm{C}, 36.37 ; \mathrm{H}, 6.49 ; \mathrm{N}, 21.20$. Found: C, 36.45; H, 6.69; N, 21.43.

\subsubsection{General procedure for the synthesis of (1,2,3-triazolyl) isoxazolidines 15 and 16}

To a solution of the azidoisoxazolidine $\mathbf{1 2}$ or $\mathbf{1 3}(1.00 \mathrm{mmol})$ in tert-butanol $(0.5 \mathrm{~mL}), \mathrm{CuSO}_{4} \cdot 4 \mathrm{H}_{2} \mathrm{O}(0.10 \mathrm{mmol})$ in water $(1 \mathrm{~mL})$ was added followed by sodium ascorbate $(0.20 \mathrm{mmol})$ and the respective alkyne $14(1.00 \mathrm{mmol})$. The reaction mixture was stirred at room temperature for $48 \mathrm{~h}$, concentrated and co-evaporated with ethanol $(3 \times 10 \mathrm{~mL})$. The residue was dissolved in chloroform $(10 \mathrm{~mL})$, dried over $\mathrm{MgSO}_{4}$, filtered through a pad of Celite and the solution was evaporated under reduced pressure. The crude product was purified on a silica gel column with chloroform:methanol (from 100:1 to 20:1, v/v) as eluent.

4.1.2.1. Diethyl 5-(4-((3,4-dihydro-2,4-dioxopyrimidin-1(2H)-yl) methyl)-1H-1,2,3-triazol-1-yl)-2-methylisoxazolidin-3-yl-3-phosphonate 15a. From azidoisoxazolidine $12(0.166 \mathrm{~g}, 0.628 \mathrm{mmol})$ and $N^{1-}$ propargyluracil $(0.094 \mathrm{~g}, 0.628 \mathrm{mmol})$, phosphonate 15a (0.222 g, $85 \%$ ) was obtained as a colourless oil after purification on silica gel with chloroform-methanol (from 50:1 to 20:1, v/v). IR (film, $\mathrm{cm}^{-1}$ ) $\nu_{\max }: 3485,3152,2993,1680,1468,1441,1250,1220,1050,1026,971$, 753; ${ }^{1} \mathrm{H}$ NMR $\left(300 \mathrm{MHz}, \mathrm{CDCl}_{3}\right) \delta: 1.35(\mathrm{t}, J=7.1 \mathrm{~Hz}, 3 \mathrm{H}), 1.36(\mathrm{t}$, $J=7.1 \mathrm{~Hz}, 3 \mathrm{H}), 2.88(\mathrm{~s}, 3 \mathrm{H}), 3.00-3.25(\mathrm{~m}, 1 \mathrm{H}), 3.40-3.55(\mathrm{~m}, 1 \mathrm{H})$, $3.58-3.65(\mathrm{~m}, 1 \mathrm{H}), 4.15-4.30(\mathrm{~m}, 4 \mathrm{H}), 4.95\left(\mathrm{AB}, 1 \mathrm{H}, J_{\mathrm{AB}}=15.5 \mathrm{~Hz}\right)$, $5.03\left(\mathrm{AB}, 1 \mathrm{H}, J_{\mathrm{AB}}=15.5 \mathrm{~Hz}\right), 5.70(\mathrm{~d}, 1 \mathrm{H}, J=7.9 \mathrm{~Hz}), 6.15(\mathrm{~d}, 1 \mathrm{H}$, $J=6.1 \mathrm{~Hz}), 7.51(\mathrm{~d}, 1 \mathrm{H}, J=7.9 \mathrm{~Hz}), 7.94(\mathrm{~s}, 1 \mathrm{H}), 9.20(\mathrm{~s}, 1 \mathrm{H}) ;{ }^{13} \mathrm{C} \mathrm{NMR}$ $\left(75.5 \mathrm{MHz}, \mathrm{CDCl}_{3}\right) \delta: 16.5(\mathrm{~d}, J=5.7 \mathrm{~Hz}), 16.6(\mathrm{~d}, J=5.7 \mathrm{~Hz}), 38.8$, 43.1, $47.8(\mathrm{~d}, J=5.4 \mathrm{~Hz}), 62.5\left(\mathrm{~d},{ }^{1} J_{\mathrm{PC}}=171.5 \mathrm{~Hz}, \mathrm{C} 3\right), 63.0(\mathrm{~d}$, $J=6.9 \mathrm{~Hz}, \quad \mathrm{C}-\mathrm{O}-\mathrm{P}), \quad 63.4 \quad(\mathrm{~d}, \quad J=6.6 \mathrm{~Hz}, \quad \mathrm{C}-\mathrm{O}-\mathrm{P}), 86.3 \quad(\mathrm{~d}$, $\left.{ }^{3} J_{\mathrm{PCCC}}=9.7 \mathrm{~Hz}, \mathrm{C} 5\right), 102.6,123.9,142.1,144.4,151.0,164.1 ;{ }^{31} \mathrm{P}$ NMR $\left(121.5 \mathrm{MHz}, \mathrm{CDCl}_{3}\right) \delta$ : 21.33. Anal. Calcd for $\mathrm{C}_{15} \mathrm{H}_{23} \mathrm{~N}_{6} \mathrm{O}_{6} \mathrm{P}: \mathrm{C}, 43.48$; H, 5.59; N, 20.28. Found: C, 43.56; H, 5.76; N, 20.38.

4.1.2.2. Diethyl 5-(4-((3,4-dihydro-2,4-dioxopyrimidin-1(2H)-yl) methyl)-1H-1,2,3-triazol-1-yl)-2-methylisoxazolidin-3-yl-3-phosphonate 16a. From azidoisoxazolidine $13(0.164 \mathrm{~g}, 0.621 \mathrm{mmol})$ and $N^{1}$-propargyluracil $(0.093 \mathrm{~g}, \quad 0.621 \mathrm{mmol})$, phosphonate 16a $(0.233 \mathrm{~g}, 91 \%)$ was obtained as a colourless oil after purification on silica gel with chloroform-methanol (20:1, v/v). IR (film, $\mathrm{cm}^{-1}$ ) $\nu_{\max }: 3464,3155,2996,1706,1690,1457,1390,1235,1110,1044$, $1020,959,755 ;{ }^{1} \mathrm{H}$ NMR $\left(300 \mathrm{MHz}, \mathrm{CDCl}_{3}\right) \delta: 1.33(\mathrm{t}, 3 \mathrm{H}, J=7.1 \mathrm{~Hz})$, $1.34(\mathrm{t}, 3 \mathrm{H}, J=7.1 \mathrm{~Hz}), 2.96(\mathrm{~d}, 3 \mathrm{H}, J=0,8 \mathrm{~Hz}), 3.00-3.20(\mathrm{~m}, 2 \mathrm{H})$, 3.20-3.40 (m, 1H), 4.00-4.25 (m, 4H), $5.00(\mathrm{~s}, 2 \mathrm{H}), 5.70(\mathrm{~d}$, $J=7.9 \mathrm{~Hz}, 1 \mathrm{H}), 6.37(\mathrm{~d}, J=6.0 \mathrm{~Hz}, 1 \mathrm{H}), 7.53(\mathrm{~d}, J=7.9 \mathrm{~Hz}, 1 \mathrm{H}), 8.20(\mathrm{~s}$, $1 \mathrm{H}), 8.87(\mathrm{~s}, 1 \mathrm{H}) ;{ }^{13} \mathrm{C} \mathrm{NMR}\left(75.5 \mathrm{MHz}, \mathrm{CDCl}_{3}\right) \delta: 16.4(\mathrm{~d}, J=5.7 \mathrm{~Hz})$, $40.2,42.6,45.6,62.9$ (d, $J=6.9 \mathrm{~Hz}, \mathrm{C}-\mathrm{O}-\mathrm{P}), 63.4\left(\mathrm{~d},{ }^{1} \mathrm{~J}_{\mathrm{PC}}=166.6 \mathrm{~Hz}\right.$, C3), 63.5 (d, $J=6.6 \mathrm{~Hz}, \mathrm{C}-\mathrm{O}-\mathrm{P}), 85.4$ (d, $\left.{ }^{3} J_{\mathrm{PCCC}}=9.2 \mathrm{~Hz}, \mathrm{C} 5\right), 102.4$, $122.3,141.9,144.4,150.8,164.2 ;{ }^{31} \mathrm{P}$ NMR $\left(121.5 \mathrm{MHz}, \mathrm{CDCl}_{3}\right) \delta$ : 21.36. Anal. Calcd for $\mathrm{C}_{15} \mathrm{H}_{23} \mathrm{~N}_{6} \mathrm{O}_{6} \mathrm{P}$ : C, 43.48; H, 5.59; N, 20.28. Found: C, 43.46; H, 5.53; N, 20.44.

4.1.2.3. Diethyl 5-(4-((3,4-dihydro-5-methyl-2,4-dioxopyrimidin1(2H)-yl)methyl)-1H-1,2,3-triazol-1-yl)-2-methylisoxazolidin-3-yl3-phosphonate 15b. From azidoisoxazolidine 12 (0.165 g, $0.628 \mathrm{mmol})$ and $N^{1}$-propargylthymine $(0.103 \mathrm{~g}, 0.628 \mathrm{mmol})$, phosphonate 15b $(0.206 \mathrm{~g}, 77 \%)$ was obtained as a colourless oil after purification on silica gel with chloroform-methanol (from 50:1 to $20: 1, \mathrm{v} / \mathrm{v}$ ). IR (film, $\mathrm{cm}^{-1}$ ) $\nu_{\text {max }}: 3454,3143,2986,1689,1458$, 1390, 1320, 1232, 1067, 1026, 973, 809, 783; ${ }^{1} \mathrm{H}$ NMR $(300 \mathrm{MHz}$, $\left.\mathrm{CDCl}_{3}\right) \delta: 1.35(\mathrm{t}, 3 \mathrm{H}, J=7.2 \mathrm{~Hz}), 1.36(\mathrm{t}, 3 \mathrm{H}, J=7.2 \mathrm{~Hz}), 1.90(\mathrm{~s}, 3 \mathrm{H})$, 2.89 (s, 3H), 3.14 (dddd, $1 \mathrm{H}, J=17.7,12.9,10.2,6.6 \mathrm{~Hz}$ ), 3.39-3.48 (m, 1H), 3.60 (ddd, $1 \mathrm{H}, J=10.2,7.2,3.3 \mathrm{~Hz}$ ), 4.10-4.35 (m, 4H), 4.91 $\left(\mathrm{AB}, 1 \mathrm{H}, J_{\mathrm{AB}}=15.0 \mathrm{~Hz}\right), 5.02\left(\mathrm{AB}, 1 \mathrm{H}, J_{\mathrm{AB}}=15.0 \mathrm{~Hz}\right), 6.15(\mathrm{~d}, 1 \mathrm{H}$, $J=6.7 \mathrm{~Hz}), 7.33(\mathrm{~s}, 1 \mathrm{H}), 7.91(\mathrm{~s}, 1 \mathrm{H}), 8.77(\mathrm{~s}, 1 \mathrm{H}) ;{ }^{13} \mathrm{C} \mathrm{NMR}(75.5 \mathrm{MHz}$, $\left.\mathrm{CDCl}_{3}\right) \delta: 12.4,16.4(\mathrm{~d}, J=5.7 \mathrm{~Hz}), 16.5(\mathrm{~d}, J=5.7 \mathrm{~Hz}), 38.8,47.7(\mathrm{~d}$, $J=5.7 \mathrm{~Hz}), 50.2,62.5\left(\mathrm{~d},{ }^{1} J_{\mathrm{PC}}=171.5 \mathrm{~Hz}, \mathrm{C} 3\right), 63.0(\mathrm{~d}, J=6.9 \mathrm{~Hz}$, C-O-P), 63.4 (d, J=6.6 Hz, C-O-P), 86.3 (d, $\left.{ }^{3} J_{\mathrm{PCCC}}=10.0 \mathrm{~Hz}, \mathrm{C} 5\right)$, $111.1,123.9,140.2,142.4,151.2,164.5 ;{ }^{31} \mathrm{P} \mathrm{NMR}\left(121.5 \mathrm{MHz}, \mathrm{CDCl}_{3}\right) \delta$ : 21.23. Anal. Calcd for $\mathrm{C}_{16} \mathrm{H}_{25} \mathrm{~N}_{6} \mathrm{O}_{6} \mathrm{P}$ : C, 44.86; $\mathrm{H}, 5.88$; N, 19.62 . Found: C, 45.07; H, 5.70; N, 19.83 .

4.1.2.4. Diethyl 5-(4-((3,4-dihydro-5-methyl-2,4-dioxopyrimidin1(2H)-yl)methyl)-1H-1,2,3-triazol-1-yl)-2-methylisoxazolidin-3-yl- 
3-phosphonate 16b. From azidoisoxazolidine 13 (0.150 g, $0.568 \mathrm{mmol})$ and $N^{1}$-propargylthymine $(0.093 \mathrm{~g}, 0.568 \mathrm{mmol})$, phosphonate 16b $(0.243 \mathrm{~g}, 98 \%)$ was obtained as a colourless oil after purification on silica gel with chloroform-methanol (from 50:1 to $20: 1, \mathrm{v} / \mathrm{v}$ ). IR (film, $\mathrm{cm}^{-1}$ ) $\nu_{\max }: 3484,3156,3058,2984$, $1690,1679,1468,1367,1236,1110,1050,1024,972,786,734 ;{ }^{1} \mathrm{H}$ NMR $\left(300 \mathrm{MHz}, \mathrm{CDCl}_{3}\right) \delta: 1.30(\mathrm{t}, 3 \mathrm{H}, J=7.1 \mathrm{~Hz}), 1.34(\mathrm{t}, 3 \mathrm{H}$, $J=7.1 \mathrm{~Hz}), 1.90(\mathrm{~s}, 3 \mathrm{H}), 2.96(\mathrm{~s}, 3 \mathrm{H}), 2.95-3.20(\mathrm{~m}, 2 \mathrm{H}), 3.20-3.40$ (m, 1H), 4.05-4.25 (m, 4H), $4.98(\mathrm{~s}, 2 \mathrm{H}), 6.36(\mathrm{~d}, 1 \mathrm{H}, J=6.3 \mathrm{~Hz}), 7.36$ $(\mathrm{s}, 1 \mathrm{H}), 8.19(\mathrm{~s}, 1 \mathrm{H}), 8.42(\mathrm{~s}, 1 \mathrm{H}) ;{ }^{13} \mathrm{C} \mathrm{NMR}\left(\mathrm{CDCl}_{3}, 75.5 \mathrm{MHz}\right) \delta: 12.4$, $16.5(\mathrm{~d}, J=5.7 \mathrm{~Hz}), 40.2,42.4,45.6,62.9(\mathrm{~d}, J=6.9 \mathrm{~Hz}, \mathrm{C}-\mathrm{O}-\mathrm{P}), 63.4$ (d, $\left.{ }^{1} J_{\mathrm{PC}}=166.3 \mathrm{~Hz}, \mathrm{C} 3\right), 63.5$ (d, $\left.J=6.6 \mathrm{~Hz}, \mathrm{C}-\mathrm{O}-\mathrm{P}\right), 85.4$ (d, $\left.{ }^{3} \mathrm{JPCC}_{\mathrm{PCC}}=9.2 \mathrm{~Hz}, \mathrm{C} 5\right), 110.9,122.2,140.2,142.2,150.9,164.6 ;{ }^{31} \mathrm{P} \mathrm{NMR}$ $\left(121.5 \mathrm{MHz}, \mathrm{CDCl}_{3}\right) \delta$ : 21.32. Anal. Calcd for $\mathrm{C}_{16} \mathrm{H}_{25} \mathrm{~N}_{6} \mathrm{O}_{6} \mathrm{P}: \mathrm{C}, 44.86$; H, 5.88; N, 19.62. Found: C, 44.77; H, 5.90; N, 19.60 .

\subsubsection{Diethyl 5-(4-((acetylamino)-2-oxopyrimidin-1(2H)-yl)} methyl)-1H-1,2,3-triazol-1-yl)-2-methylisoxazolidin-3-yl-3-phosphonate 15c. From azidoisoxazolidine $12(0.169 \mathrm{~g}, 0.640 \mathrm{mmol})$ and $\quad N$-(1,2-dihydro-2-oxo-1-(prop-2-ynyl)pyrimidin-4-yl)acetamide $(0.122 \mathrm{~g}, 0.640 \mathrm{mmol})$, phosphonate $15 \mathrm{c}(0.224 \mathrm{~g}, 77 \%)$ was obtained as a colourless oil after purification on silica gel with chloroform-methanol (from 50:1 to 20:1, v/v). IR (film, $\mathrm{cm}^{-1}$ ) $\nu_{\max }$ : 3446, 2928, 1654, 1559, 1490, 1374, 1307, 1221, 1024, 962, 792; ${ }^{1} \mathrm{H}$ $\operatorname{NMR}\left(300 \mathrm{MHz}, \mathrm{CDCl}_{3}\right) \delta: 1.35(\mathrm{t}, J=7.2 \mathrm{~Hz}, 3 \mathrm{H}), 1.36(\mathrm{t}, J=7.2 \mathrm{~Hz}$, $3 \mathrm{H}), 2.25(\mathrm{~s}, 3 \mathrm{H}), 2.87(\mathrm{~s}, 3 \mathrm{H}), 3.14$ (dddd, $1 \mathrm{H}, J=17.4,13.3,10.9$, $6.7 \mathrm{~Hz}$ ), 3.40 (dddd, $1 \mathrm{H}, J=13.3,6.9,5.0,1.8 \mathrm{~Hz}$ ), 3.63 (ddd, $1 \mathrm{H}$, $J=10.5,6.9,3.0 \mathrm{~Hz}), 4.15-4.27(\mathrm{~m}, 4 \mathrm{H}), 5.10\left(\mathrm{AB}, 1 \mathrm{H}, J_{\mathrm{AB}}=14.5 \mathrm{~Hz}\right)$, $5.20\left(\mathrm{AB}, 1 \mathrm{H}, J_{\mathrm{AB}}=14.5 \mathrm{~Hz}\right), 6.20(\mathrm{dd}, 1 \mathrm{H}, J=6.7,1.8 \mathrm{~Hz}), 7.42(\mathrm{~d}, 1 \mathrm{H}$, $J=7.1 \mathrm{~Hz}), 7.96$ (d, $1 \mathrm{H}, J=7.1 \mathrm{~Hz}), 8.09$ (s, 1H), 9.40 (br s, $1 \mathrm{H}) ;{ }^{13} \mathrm{C}$ NMR (75.5 MHz, $\left.\mathrm{CDCl}_{3}\right) \delta: 16.6(\mathrm{~d}, J=3.7 \mathrm{~Hz}), 24.9,38.9,45.1,47.8$ $\left(\mathrm{d}, J=6.0 \mathrm{~Hz}, \mathrm{CH}_{3}-\mathrm{N}\right), 62.7\left(\mathrm{~d},{ }^{1} J_{\mathrm{PC}}=171.5 \mathrm{~Hz}, \mathrm{C} 3\right), 63.1 \quad(\mathrm{~d}$, $J=6.9 \mathrm{~Hz}, \quad \mathrm{C}-\mathrm{O}-\mathrm{P}), \quad 63.4 \quad(\mathrm{~d}, \quad J=6.6 \mathrm{~Hz}, \quad \mathrm{C}-\mathrm{O}-\mathrm{P}), 86.4 \quad$ (d, $\left.{ }^{3} J_{\text {PCCC }}=9.4 \mathrm{~Hz}, \mathrm{C} 5\right), 97.3,124.3,142.1,148.9,155.8,163.0,171.1 ;{ }^{31} \mathrm{P}$ NMR $\left(\mathrm{CDCl}_{3}, 121.5 \mathrm{MHz}\right) \delta: 20.82$. Anal. Calcd for $\mathrm{C}_{17} \mathrm{H}_{26} \mathrm{~N}_{7} \mathrm{O}_{6} \mathrm{P}: \mathrm{C}$, 44.84; H, 5.75; N, 21.53. Found: C, 44.93; H, 5.76; N, 21.67.

4.1.2.6. Diethyl 5-(4-((acetylamino)-2-oxopyrimidin-1(2H)-yl) methyl)-1H-1,2,3-triazol-1-yl)-2-methylisoxazolidin-3-yl-3-phosphonate 16c. From azidoisoxazolidine $13(0.203 \mathrm{~g}, 0.768 \mathrm{mmol})$ and $\quad N$-(1,2-dihydro-2-oxo-1-(prop-2-ynyl)pyrimidin-4-yl)acetamide $(0.147 \mathrm{~g}, 0.768 \mathrm{mmol})$, phosphonate $16 \mathrm{c}(0.325 \mathrm{~g}, 93 \%)$ was obtained as a colourless oil after purification on silica gel with chloroform-methanol (from 50:1 to 20:1, v/v). IR (film, $\mathrm{cm}^{-1}$ ) $\nu_{\text {max }}$ : 3446, 2982, 2924, 1718, 1684, 1662, 1600, 1497, 1374, 1308, 1240, 1050, 1025, 952, 797; ${ }^{1} \mathrm{H}$ NMR $\left(300 \mathrm{MHz}, \mathrm{CDCl}_{3}\right) \delta: 1.31(\mathrm{t}, 3 \mathrm{H}$, $J=7.1 \mathrm{~Hz}$,), $1.34(\mathrm{t}, 3 \mathrm{H}, J=7.1 \mathrm{~Hz}),, 2.24(\mathrm{~s}, 3 \mathrm{H}), 2.96(\mathrm{~d}, 3 \mathrm{H}$, $J=1.0 \mathrm{~Hz},), 3.00-3.10(\mathrm{~m}, 2 \mathrm{H}), 3.10-3.20(\mathrm{~m}, 1 \mathrm{H}), 4.00-4.20(\mathrm{~m}$, $4 \mathrm{H}), 5.17(\mathrm{~s}, 2 \mathrm{H}), 6.35$ (dd, $1 \mathrm{H}, J=7.3,2.2 \mathrm{~Hz}), 7.38(\mathrm{~d}, 1 \mathrm{H}, J=7.3 \mathrm{~Hz})$, $7.96(\mathrm{~d}, 1 \mathrm{H}, J=7.3 \mathrm{~Hz}), 8.25(\mathrm{~s}, 1 \mathrm{H}), 9.00$ (br s, $1 \mathrm{H}) ;{ }^{13} \mathrm{C}$ NMR $\left(75.5 \mathrm{MHz}, \mathrm{CDCl}_{3}\right) \delta: 16.4(\mathrm{~d}, J=5.7 \mathrm{~Hz}), 24.8,40.0,44.8,45.5(\mathrm{~s}$, $\left.\mathrm{CH}_{3}-\mathrm{N}\right), 62.9(\mathrm{~d}, J=6.9 \mathrm{~Hz}, \mathrm{C}-\mathrm{O}-\mathrm{P}), 63.4\left(\mathrm{~d},{ }^{1} J_{\mathrm{PC}}=166.3 \mathrm{~Hz}, \mathrm{C} 3\right)$, $63.5(\mathrm{~d}, J=6.6 \mathrm{~Hz}, \mathrm{C}-\mathrm{O}-\mathrm{P}), 85.4\left(\mathrm{~d},{ }^{3} \mathrm{JPCCC}_{\mathrm{PC}}=9.2 \mathrm{~Hz}, \mathrm{C} 5\right), 97.0,122.6$, 141.8, 148.9, 155.6, 162.9, 171.2; ${ }^{31} \mathrm{P}$ NMR $\left(\mathrm{CDCl}_{3}, 121.5 \mathrm{MHz}\right) \delta: 20.53$. Anal. Calcd for $\mathrm{C}_{17} \mathrm{H}_{26} \mathrm{~N}_{7} \mathrm{O}_{6} \mathrm{P}$ : C, 44.84; $\mathrm{H}, 5.75$; N, 21.53. Found: $\mathrm{C}$, 44.79; H, 5.64; N, 21.60.

4.1.2.7. Diethyl 5-(4-((6-amino-9H-purin-9-yl)methyl)-1H-1,2,3triazol-1-yl)-2-methylisoxazolidin-3-yl-3-phosphonate 15d. From azidoisoxazolidine $12(0.150 \mathrm{~g}, 0.568 \mathrm{mmol})$ and $N^{9}$-(propargyl) adenine $(0.098 \mathrm{~g}, 0.568 \mathrm{mmol})$, phosphonate 15d $(0.204 \mathrm{~g}, 82 \%)$ was obtained as a white amorphous solid after purification on silica gel with chloroform-methanol (from 50:1 to 20:1, v/v). M.p.: $100-102{ }^{\circ} \mathrm{C}$. IR $\left(\mathrm{KBr}, \mathrm{cm}^{-1}\right) \nu_{\max }: 3445,3301,3137,2984,1665,1600$, 1474, 1418, 1322, 1249, 1050, 1023, 969, 776; ${ }^{1} \mathrm{H}$ NMR (300 MHz,
$\left.\mathrm{CDCl}_{3}\right) \delta: 1.33(\mathrm{t}, 3 \mathrm{H}, J=7.0 \mathrm{~Hz}), 1.34(\mathrm{t}, 3 \mathrm{H}, J=7.0 \mathrm{~Hz}), 2.82(\mathrm{~s}, 3 \mathrm{H})$, 3.10 (dddd, $1 \mathrm{H}, J=17.4,12.6,10.2,6.6 \mathrm{~Hz}), 3.60-4.30(\mathrm{~m}, 2 \mathrm{H})$, $4.10-4.30(\mathrm{~m}, 4 \mathrm{H}), 5.50(\mathrm{~s}, 2 \mathrm{H}), 6.01(\mathrm{~s}, 2 \mathrm{H}), 6.08(\mathrm{~d}, 1 \mathrm{H}, J=6.6 \mathrm{~Hz}$, $\mathrm{H}$-C5), 7.88, (s, 1H), $8.00(\mathrm{~s}, 1 \mathrm{H}), 8.35(\mathrm{~s}, 1 \mathrm{H}) ;{ }^{13} \mathrm{C}$ NMR $(75.5 \mathrm{MHz}$, $\left.\mathrm{CDCl}_{3}\right) \delta: 16.5(\mathrm{~d}, J=5.4 \mathrm{~Hz}), 16.6(\mathrm{~d}, J=5.7 \mathrm{~Hz}), 38.5,38.7,47.9(\mathrm{~d}$, $J=5.7 \mathrm{~Hz}), 62.5\left(\mathrm{~d},{ }^{1} J_{\mathrm{PC}}=172.0 \mathrm{~Hz}, \mathrm{C} 3\right), 63.0(\mathrm{~d}, J=6.9 \mathrm{~Hz}, \mathrm{C}-\mathrm{O}-\mathrm{P})$, $63.4(\mathrm{~d}, J=6.6 \mathrm{~Hz}, \mathrm{C}-\mathrm{O}-\mathrm{P}), 86.4\left(\mathrm{~d},{ }^{3} \mathrm{JPCCC}_{\mathrm{PCC}}=9.7 \mathrm{~Hz}, \mathrm{C} 5\right), 119.0,123.1$, 140.1, 142.7, 149.2, 152.7, 155.7; ${ }^{31} \mathrm{P}$ NMR $\left(121.5 \mathrm{MHz}, \mathrm{CDCl}_{3}\right) \delta$ : 21.38. Anal. Calcd for $\mathrm{C}_{16} \mathrm{H}_{24} \mathrm{~N}_{9} \mathrm{O}_{4} \mathrm{P}$ : C, 43.94; $\mathrm{H}, 5.53 ; \mathrm{N}, 28.82$. Found: C, 44.03; H, 5.30; N, 29.01.

4.1.2.8. Diethyl 5-(4-((6-amino-9H-purin-9-yl)methyl)-1H-1,2,3triazol-1-yl)-2-methylisoxazolidin-3-yl-3-phosphonate 16d. From azidoisoxazolidine $13(0.150 \mathrm{~g}, 0.568 \mathrm{mmol})$ and $N^{9}$-(propargyl) adenine $(0.098 \mathrm{~g}, 0.568 \mathrm{mmol})$, phosphonate 16d $(0.207 \mathrm{~g}, 83 \%)$ was obtained as a white amorphous solid after purification on silica gel with chloroform-methanol (from 50:1 to 20:1, v/v). M.p.: 139-140 ${ }^{\circ} \mathrm{C}$. IR $\left(\mathrm{KBr}, \mathrm{cm}^{-1}\right) \nu_{\text {max }}: 3292,2983,1665,1600,1475,1304$, 1243, 1115, 1050, 1019, 960, 777; ${ }^{1} \mathrm{H}$ NMR (300 MHz, $\left.\mathrm{CDCl}_{3}\right) \delta: 1.21$ $(\mathrm{t}, 3 \mathrm{H}, J=7.1 \mathrm{~Hz}), 1.29(\mathrm{t}, 3 \mathrm{H}, J=7.1 \mathrm{~Hz}), 2.93(\mathrm{~s}, 3 \mathrm{H}), 2.98-3.17(\mathrm{~m}$, $2 \mathrm{H}), 3.20-3.40(\mathrm{~m}, 1 \mathrm{H}), 4.00-4.20(\mathrm{~m}, 4 \mathrm{H}), 5.49(\mathrm{~s}, 2 \mathrm{H}), 5.99$ (br s, $2 \mathrm{H}), 6.35$ (d, 1H, J=6.1 Hz, H-C5), $8.01(\mathrm{~s}, 1 \mathrm{H}), 8.18(\mathrm{~s}, 1 \mathrm{H}), 8.35$ (s, $1 \mathrm{H}) ;{ }^{13} \mathrm{C}$ NMR $\left(75.5 \mathrm{MHz}, \mathrm{CDCl}_{3}\right) \delta: 16.4(\mathrm{~d}, J=5.4 \mathrm{~Hz}), 16.2(\mathrm{~d}$, $J=5.7 \mathrm{~Hz}), 38.4,40.2,45.6\left(\mathrm{~s}, \mathrm{CH}_{3}-\mathrm{N}\right), 62.8(\mathrm{~d}, J=6.9 \mathrm{~Hz}, \mathrm{C}-\mathrm{O}-\mathrm{P})$, $63.3(\mathrm{~d}, J=6.9 \mathrm{~Hz}, \mathrm{C}-\mathrm{O}-\mathrm{P}), 63.3\left(\mathrm{~d},{ }^{1} \mathrm{~J}_{\mathrm{PC}}=166.6 \mathrm{~Hz}, \mathrm{C} 3\right), 85.4(\mathrm{~d}$, $\left.{ }^{3} \mathrm{JCCC}_{\mathrm{PCC}}=9.2 \mathrm{~Hz}, \mathrm{C} 5\right), 119.1,121.6,140.2,142.4,149.4,152.8,155.8 ;{ }^{31} \mathrm{P}$ NMR (121.5 MHz, $\mathrm{CDCl}_{3}$ ): 21.44. Anal. Calcd for $\mathrm{C}_{16} \mathrm{H}_{24} \mathrm{~N}_{9} \mathrm{O}_{4} \mathrm{P}$ : C, 43.94; H, 5.53; N, 28.82. Found: C, 43.76; H, 5.60; N, 28.71.

4.1.2.9. Diethyl 5-(4-(methoxycarbonyl)-1H-1,2,3-triazol-1-yl)-2methylisoxazolidin-3-yl-3-phosphonate 15e. From azidoisoxazolidine $12(0.150 \mathrm{~g}, 0.568 \mathrm{mmol})$ and methyl propiolate (0.051 mL, $0.568 \mathrm{mmol})$, phosphonate $15 \mathrm{e}(0.168 \mathrm{~g}, 85 \%)$ was obtained as colourless needles after purification on silica gel with chloroform-methanol (from 50:1 to 20:1, v/v). M.p.: 78-80 ${ }^{\circ} \mathrm{C}$. IR $\left(\mathrm{KBr}, \mathrm{cm}^{-1}\right) \nu_{\max }: 3457,2989,2923,1744,1445,1257,1202,1046$, 1020, 804; ${ }^{1} \mathrm{H}$ NMR $\left(300 \mathrm{MHz}, \mathrm{CDCl}_{3}\right) \delta: 1.37(\mathrm{t}, 3 \mathrm{H}, J=7.0 \mathrm{~Hz}$, $\left.\mathrm{POCH}_{2} \mathrm{CH}_{3}\right), 1.38\left(\mathrm{t}, 3 \mathrm{H}, J=7.0 \mathrm{~Hz}, \mathrm{POCH}_{2} \mathrm{CH}_{3}\right), 2.90\left(\mathrm{~s}, 3 \mathrm{H}, \mathrm{CH}_{3}-\mathrm{N}\right)$, 3.10 (dddd, $1 \mathrm{H}, J=17.4,13.1,10.8,6.9 \mathrm{~Hz}, \mathrm{HbC}), 3.45-3.60(\mathrm{~m}, 2 \mathrm{H})$, $3.98\left(\mathrm{~s}, 3 \mathrm{H}, \mathrm{COOCH}_{3}\right), 4.17-4.30\left(\mathrm{~m}, 4 \mathrm{H}, 2 \times \mathrm{POCH}_{2} \mathrm{CH}_{3}\right), 6.20$ (dd, $1 \mathrm{H}, J=6.5,1.0 \mathrm{~Hz}, \mathrm{HC} 5), 8.31\left(\mathrm{~s}, 1 \mathrm{H}, H C 5^{\prime}\right) ;{ }^{1} \mathrm{H}$ NMR $(300 \mathrm{MHz}$, $\left.\mathrm{C}_{6} \mathrm{D}_{6},\right) \delta: 1.00\left(\mathrm{t}, 3 \mathrm{H}, J=6.9 \mathrm{~Hz}, \mathrm{POCH}_{2} \mathrm{CH}_{3}\right), 1.54(\mathrm{t}, 3 \mathrm{H}, J=6.9 \mathrm{~Hz}$, $\mathrm{POCH}_{2} \mathrm{CH}_{3}$ ), 2.69 (d, $3 \mathrm{H}, J=0.4 \mathrm{~Hz}, \mathrm{CH}_{3}-\mathrm{N}$ ), 2.84 (dddd, $1 \mathrm{H}, J=17.4$, 13.1, 10.8, $6.9 \mathrm{~Hz}, \mathrm{HbC}$ ), 3.13 (dddd, $1 \mathrm{H}, J=13.1,6.8,4.7,1.6 \mathrm{~Hz}$, $\mathrm{HaC} 4$ ), 3.47 (ddd, $1 \mathrm{H}, J=10.8,6.8,2.8 \mathrm{~Hz}, \mathrm{HC} 3), 3.16(\mathrm{~s}, 3 \mathrm{H}$, $\left.\mathrm{COOCH}_{3}\right), \quad 3.86-3.99\left(\mathrm{~m}, 2 \mathrm{H}, \mathrm{POCH}_{2} \mathrm{CH}_{3}\right), 4.01-4.07(\mathrm{~m}, 2 \mathrm{H}$, $\left.\mathrm{POCH}_{2} \mathrm{CH}_{3}\right), 5.24(\mathrm{dd}, 1 \mathrm{H}, J=6.9,1.6 \mathrm{~Hz}, \mathrm{HC} 5), 7.55\left(\mathrm{~s}, 1 \mathrm{H}, \mathrm{HC}^{\prime}\right) ;{ }^{13} \mathrm{C}$ NMR (75.5 MHz, $\left.\mathrm{CDCl}_{3}\right) \delta: 16.70(\mathrm{~d}, J=5.8 \mathrm{~Hz}), 16.8(\mathrm{~d}, J=5.7 \mathrm{~Hz})$, $39.3(\mathrm{~s}, \mathrm{C} 4), 48.2\left(\mathrm{~s}, \mathrm{CH}_{3}-\mathrm{N}\right), 52.6\left(\mathrm{~s}, \mathrm{COOCH}_{3}\right), 62.7(\mathrm{~d}$, $\left.{ }^{1} J_{\mathrm{PC}}=171.8 \mathrm{~Hz}, \mathrm{C} 3\right), 63.2(\mathrm{~d}, J=6.9 \mathrm{~Hz}, \mathrm{C}-\mathrm{O}-\mathrm{P}), 63.7(\mathrm{~d}, J=6.6 \mathrm{~Hz}$, C-O-P), $87.0\left(\mathrm{~d},{ }^{3} \mathrm{JPCC}_{\mathrm{PCC}}=10.0 \mathrm{~Hz}, \mathrm{C} 5\right), 127.4\left(\mathrm{~s}, \mathrm{C}^{\prime}\right), 140.5\left(\mathrm{~s}, \mathrm{C}^{\prime}\right)$, 160.9 (s, C=O); ${ }^{31} \mathrm{P}$ NMR $\left(121.5 \mathrm{MHz}, \mathrm{CDCl}_{3}\right) \delta: 21.03 .{ }^{31} \mathrm{P}$ NMR $\left(\mathrm{C}_{6} \mathrm{D}_{6}, 121.5 \mathrm{MHz}\right): 21.33$. Anal. Calcd for $\mathrm{C}_{12} \mathrm{H}_{21} \mathrm{~N}_{4} \mathrm{O}_{6} \mathrm{P}: \mathrm{C}, 41.38 ; \mathrm{H}$, 6.08; N, 16.09. Found: C, 41.42; H, 5.99; N, 16.20.

4.1.2.10. Diethyl 5-(4-(methoxycarbonyl)-1H-1,2,3-triazol-1-yl)-2methylisoxazolidin-3-yl-3-phosphonate 16e. From azidoisoxazolidine $13(0.150 \mathrm{~g}, 0.568 \mathrm{mmol})$ and methyl propiolate (0.051 mL, $0.568 \mathrm{mmol})$, phosphonate $16 \mathrm{e}(0.168 \mathrm{~g}, 85 \%)$ was obtained as a colourless oil after purification on silica gel with chloroform-methanol (from 50:1 to 20:1, v/v). IR (film, $\mathrm{cm}^{-1}$ ) $\nu_{\max }$ : 3480, 3156, 2983, 1741, 1545, 1440, 1368, 1241, 1200, 1163, 1098, 1050, 1026, 972, 809, 779; ${ }^{1} \mathrm{H}$ NMR $\left(300 \mathrm{MHz}, \mathrm{C}_{6} \mathrm{D}_{6}\right) \delta: 0.96(\mathrm{t}, 3 \mathrm{H}$, $\left.J=7.2 \mathrm{~Hz}, \mathrm{POCH}_{2} \mathrm{CH}_{3}\right), 1.01\left(\mathrm{t}, 3 \mathrm{H}, J=7.2 \mathrm{~Hz}, \mathrm{POCH}_{2} \mathrm{CH}_{3}\right.$ ), 2.41 (dddd, $1 \mathrm{H}, J=13.5,9.9,7.9,5.4 \mathrm{~Hz}, \mathrm{HbC} 4), 2.53$ (ddd, $1 \mathrm{H}, J=9.9,8.1,1.8 \mathrm{~Hz}$, 
HC3), 2.74 (dddd, 1H, $J=17.2,13.5,8.1,2.0 \mathrm{~Hz}, \mathrm{HaC} 4), 2.76$ (d, 3H, $\left.J=1.0 \mathrm{~Hz}, \mathrm{CH}_{3}-\mathrm{N}\right), 3.48\left(\mathrm{~s}, 3 \mathrm{H}, \mathrm{COOCH}_{3}\right), 3.93-3.75(\mathrm{~m}, 4 \mathrm{H}, 2 \times$ $\left.\mathrm{POCH}_{2} \mathrm{CH}_{3}\right), 5.87(\mathrm{dd}, 1 \mathrm{H}, J=7.9,2.0 \mathrm{~Hz}, \mathrm{HC} 5), 8.74\left(\mathrm{~s}, 1 \mathrm{H}, \mathrm{HC}^{\prime}\right) ;{ }^{13} \mathrm{C}$ $\operatorname{NMR}\left(75.5 \mathrm{MHz}, \mathrm{CDCl}_{3}\right) \delta: 16.70(\mathrm{~d}, J=5.5 \mathrm{~Hz}), 16.6(\mathrm{~d}, J=5.7 \mathrm{~Hz})$, $40.8\left(\mathrm{~d},{ }^{2} J_{\mathrm{PCC}}=2.0 \mathrm{~Hz}, \mathrm{C} 4\right), 45.7\left(\mathrm{~d}, J=1.7 \mathrm{~Hz}, \mathrm{CH}_{3}-\mathrm{N}\right), 52.3(\mathrm{~s}$, $\left.\mathrm{COOCH}_{3}\right), 63.0(\mathrm{~d}, J=6.8 \mathrm{~Hz}, \mathrm{C}-\mathrm{O}-\mathrm{P}), 63.4\left(\mathrm{~d},{ }^{1} J_{\mathrm{PC}}=166.9 \mathrm{~Hz}, 140.0\right.$ $\left.\left(\mathrm{s}, \mathrm{C} 4^{\prime}\right), \mathrm{C} 3\right), 63.5(\mathrm{~d}, J=6.9 \mathrm{~Hz}, \mathrm{C}-\mathrm{O}-\mathrm{P}), 85.7\left(\mathrm{~d},{ }^{3} \mathrm{JPCC}_{\mathrm{PCC}}=8.6 \mathrm{~Hz}, \mathrm{C} 5\right)$, 126.6 (s, $\left.\mathrm{C}^{\prime}\right), 161.1(\mathrm{~s}, \mathrm{C}=\mathrm{O}) ;{ }^{31} \mathrm{P}$ NMR $\left(121.5 \mathrm{MHz}, \mathrm{CDCl}_{3}\right) \delta$ : 21.12; ${ }^{31} \mathrm{P}$ NMR (121.5 MHz, $\left.\mathrm{C}_{6} \mathrm{D}_{6}\right) \delta: 21.30$. Anal. Calcd for $\mathrm{C}_{12} \mathrm{H}_{21} \mathrm{~N}_{4} \mathrm{O}_{6} \mathrm{P}: \mathrm{C}$, 41.38; H, 6.08; N, 16.09. Found: C, 41.23; H, 6.18; N, 16.28.

4.1.2.11. Diethyl 2-methyl-5-(4-phenyl-1H-1,2,3-triazol-1-yl)isoxazolidin-3-yl-3-phosphonate 15f. From azidoisoxazolidine 12 $(0.130 \mathrm{~g}, \quad 0.492 \mathrm{mmol})$ and phenylacetylene $(0.054 \mathrm{~mL}$, $0.492 \mathrm{mmol})$, phosphonate $\mathbf{1 5 f}(0.157 \mathrm{~g}, 87 \%)$ was obtained as a colourless oil after purification on silica gel with chloroform-methanol (from 50:1 to 20:1, v/v). IR (film, $\mathrm{cm}^{-1}$ ) $\nu_{\max }$ : 3469, 3129, 2983, 2910, 1484, 1441, 1250, 1235, 1160, 1060, 1027, 972, 768, 698; ${ }^{1} \mathrm{H}$ NMR (300 MHz, $\left.\mathrm{C}_{6} \mathrm{D}_{6}\right) \delta: 1.02(\mathrm{t}, 3 \mathrm{H}, J=7.2 \mathrm{~Hz}$, $\left.\mathrm{POCH}_{2} \mathrm{CH}_{3}\right), 1.08\left(\mathrm{t}, 3 \mathrm{H}, J=7.2 \mathrm{~Hz}, \mathrm{POCH}_{2} \mathrm{CH}_{3}\right), 2.77\left(\mathrm{~s}, 3 \mathrm{H}, \mathrm{CH}_{3}-\mathrm{N}\right)$, 2.93 (dddd, $1 \mathrm{H}, J=17.1,12.9, J=10.8,6.6 \mathrm{~Hz}, \mathrm{HbC}$ ), 3.38 (dddd, $1 \mathrm{H}$, $J=12.9,6.9,5.4,1.5 \mathrm{~Hz}, \mathrm{HaC} 4$ ), 3.66 (ddd, $1 \mathrm{H}, J=10.8,6.9,2.4 \mathrm{~Hz}$, HC3), 3.90-3.98 (m, $\left.2 \mathrm{H}, \mathrm{POCH}_{2} \mathrm{CH}_{3}\right), 4.01-4.12\left(\mathrm{~m}, 2 \mathrm{H}, \mathrm{POCH}_{2} \mathrm{CH}_{3}\right)$, $5.40(\mathrm{dd}, 1 \mathrm{H}, J=6.6,1.5 \mathrm{~Hz}, \mathrm{HC} 5), 7.08(\mathrm{~s}, 1 \mathrm{H}), 7.09-7.42(\mathrm{~m}, 3 \mathrm{H})$, 7.90-7.93 (m, 2H); ${ }^{13} \mathrm{C}$ NMR (75.5 MHz, $\left.\mathrm{CDCl}_{3}\right) \delta: 16.8$ (d, $J=5.7 \mathrm{~Hz}$ ), 16.9 (d, $J=5.7 \mathrm{~Hz}), 38.9$ (s, C4), 48.4 (d, $J=6.3 \mathrm{~Hz}$, $\left.\mathrm{CH}_{3}-\mathrm{N}\right), 63.0\left(\mathrm{~d},{ }^{1} J_{\mathrm{PC}}=172.6 \mathrm{~Hz}, \mathrm{C} 3\right), 63.3(\mathrm{~d}, J=6.9 \mathrm{~Hz}, \mathrm{C}-\mathrm{O}-\mathrm{P})$, $63.7(\mathrm{~d}, J=6.9 \mathrm{~Hz}, \mathrm{C}-\mathrm{O}-\mathrm{P}), 86.7\left(\mathrm{~d},{ }^{3} \mathrm{JPCCC}=9.7 \mathrm{~Hz}, \mathrm{C} 5\right), 119.7,125.9$, 129.0, 129.1, 130.2, 148.5; ${ }^{31} \mathrm{P}$ NMR (121.5 MHz, $\left.\mathrm{CDCl}_{3}\right) \delta: 21.63 ;{ }^{31} \mathrm{P}$ NMR (121.5 MHz, $\left.\mathrm{C}_{6} \mathrm{D}_{6}\right) \delta$ : 21.68. Anal. Calcd for $\mathrm{C}_{16} \mathrm{H}_{23} \mathrm{~N}_{4} \mathrm{O}_{4} \mathrm{P}: \mathrm{C}$, 52.46; H, 6.33; N, 15.29. Found: C, 52.45; H, 6.32; N, 15.25 .

4.1.2.12. Diethyl 2-methyl-5-(4-phenyl-1H-1,2,3-triazol-1-yl)isoxazolidin-3-yl-3-phosphonate 16f. From azidoisoxazolidine 13 $(0.100 \mathrm{~g}, \quad 0.378 \mathrm{mmol})$ and phenylacetylene $(0.042 \mathrm{~mL}$, $0.378 \mathrm{mmol})$, phosphonate $\mathbf{1 6 f}(0.124 \mathrm{~g}, 89 \%)$ was obtained as a white amorphous solid after purification on silica gel with chloroform-methanol (from 100:1 to 50:1, v/v). M.p.: 80-81 ${ }^{\circ} \mathrm{C}$. IR $\left(\mathrm{KBr}, \mathrm{cm}^{-1}\right) \nu_{\max }: 3522,2455,2988,2891,1609,1430,1250,1053$, 1027, 949; ${ }^{1} \mathrm{H}$ NMR $\left(300 \mathrm{MHz}, \mathrm{C}_{6} \mathrm{D}_{6}\right) \delta: 0.93(\mathrm{t}, 3 \mathrm{H}, J=7.2 \mathrm{~Hz}$, $\mathrm{POCH}_{2} \mathrm{CH}_{3}$ ), 0.95 (t, $J=7.2 \mathrm{~Hz}, 3 \mathrm{H}, \mathrm{POCH}_{2} \mathrm{CH}_{3}$ ), 2.41 (dddd, $1 \mathrm{H}$, $J=13.8,9.9,7.8,6.0 \mathrm{~Hz}, \mathrm{HaC} 4), 2.82\left(\mathrm{~d}, 3 \mathrm{H}, J=1.0 \mathrm{~Hz}, \mathrm{CH}_{3}-\mathrm{N}\right), 2.56$ (ddd, $1 \mathrm{H}, J=9.9,8.4,2.4 \mathrm{~Hz}, \mathrm{HC} 3$ ), 2.92 (dddd, $1 \mathrm{H}, J=18.0,13.8,8.4$, $2.4 \mathrm{~Hz}, \mathrm{HbC} 4)$, 3.75-3.92 (m, $4 \mathrm{H}, \mathrm{POCH}_{2} \mathrm{CH}_{3}$ ), 5.95 (dd, $1 \mathrm{H}, J=7.8$, $2.4 \mathrm{~Hz}, \mathrm{HC} 5), 7.00-7.20(\mathrm{~m}, 3 \mathrm{H}), 8.02-8.06(\mathrm{~m}, 2 \mathrm{H}), 8.46(\mathrm{~s}, 1 \mathrm{H}) ;{ }^{13} \mathrm{C}$ $\operatorname{NMR}\left(75.5 \mathrm{MHz}, \mathrm{CDCl}_{3}\right) \delta: 16.8(\mathrm{~d}, J=5.7 \mathrm{~Hz}), 40.6(\mathrm{~s}, \mathrm{C} 4), 45.9$ (d, $\left.J=1.7 \mathrm{~Hz}, \mathrm{CH}_{3}-\mathrm{N}\right), 63.1$ (d, $\left.J=6.9 \mathrm{~Hz}, \mathrm{C}-\mathrm{O}-\mathrm{P}\right), 63.5$ (d, $J=6.9 \mathrm{~Hz}$, C-O-P), 63.7 (d, $\left.{ }^{1} J_{\mathrm{PC}}=166.9 \mathrm{~Hz}, \mathrm{C} 3\right), 85.6\left(\mathrm{~d},{ }^{3} \mathrm{JPCC}=9.2 \mathrm{~Hz}, \mathrm{C} 5\right)$, 118.6, 125.9, 128.2, 128.9, 130.7, 148.1; ${ }^{31} \mathrm{P}$ NMR (121.5 MHz, $\left.\mathrm{CDCl}_{3}\right)$ $\delta$ : 21.04; ${ }^{31} \mathrm{P}$ NMR $\left(121.5 \mathrm{MHz}, \mathrm{C}_{6} \mathrm{D}_{6}\right) \delta$ : 21.99. Anal. Calcd for $\mathrm{C}_{16} \mathrm{H}_{23} \mathrm{~N}_{4} \mathrm{O}_{4} \mathrm{P}: \mathrm{C}, 52.46 ; \mathrm{H}, 6.33 ; \mathrm{N}, 15.29$. Found: C, 52.29; H, 6.52; N, 15.20 .

4.1.2.13. Diethyl 5-(4-(2-fluorophenyl)-1H-1,2,3-triazol-1-yl)-2methylisoxazolidin-3-yl-3-phosphonate 15g. From azidoisoxazolidine 12 (0.102 g, $0.386 \mathrm{mmol})$ and 1-ethynyl-2-fluorobenzene (0.043 mL, $0.386 \mathrm{mmol})$, phosphonate $15 \mathrm{~g}(0.122 \mathrm{~g}, 82 \%)$ was obtained as a white amorphous solid after purification on silica gel with chloroform-methanol (from 100:1 to 50:1, v/v). M.p.: $102-105^{\circ} \mathrm{C} . \mathrm{IR}\left(\mathrm{KBr}, \mathrm{cm}^{-1}\right) \nu_{\max }: 3426,2983,2922,1488,1437,1243$, 1047, 1027, 948, 762; ${ }^{1} \mathrm{H}$ NMR (300 MHz, $\left.\mathrm{C}_{6} \mathrm{D}_{6}\right) \delta: 1.01(\mathrm{t}, 3 \mathrm{H}$, $\left.J=7.1 \mathrm{~Hz}, \mathrm{POCH}_{2} \mathrm{CH}_{3}\right), 1.07\left(\mathrm{t}, 3 \mathrm{H}, J=7.1 \mathrm{~Hz}, \mathrm{POCH}_{2} \mathrm{CH}_{3}\right), 2.78(\mathrm{~s}, 3 \mathrm{H}$, $\mathrm{CH}_{3}-\mathrm{N}$ ), 2.90 (dddd, $1 \mathrm{H}, J=16.9,13.2,11.1,6.9, \mathrm{HbC}$ ), 3.30 (dd, $1 \mathrm{H}$, $J=13.2,6.9,4.5,1.5 \mathrm{~Hz}, \mathrm{HaC} 4), 3.67$ (ddd, $1 \mathrm{H}, J=10.8,6.9,2.1 \mathrm{~Hz}$, HC3), $3.87-4.10\left(\mathrm{~m}, 4 \mathrm{H}, 2 \times \mathrm{POCH}_{2} \mathrm{CH}_{3}\right), 5.34$ (dd, $1 \mathrm{H}, J=6.9,1.5 \mathrm{~Hz}$,
HC5), 6.83-6.93 (m, 3H), $7.69(\mathrm{~d}, J=3.8 \mathrm{~Hz}, 1 \mathrm{H}), 8.62-8.68(\mathrm{~m}, 1 \mathrm{H})$; ${ }^{13} \mathrm{C}$ NMR $\left(75.5 \mathrm{MHz}, \mathrm{CDCl}_{3}\right) \delta: 16.7(\mathrm{~d}, J=5.7 \mathrm{~Hz}), 16.8(\mathrm{~d}, J=5.4 \mathrm{~Hz})$, 38.9 (d, $J=1.7 \mathrm{~Hz}, \mathrm{C} 4), 48.3$ (d, $\left.J=6.3 \mathrm{~Hz}, \mathrm{CH}_{3}-\mathrm{N}\right), 62.9$ (d, $\left.{ }^{1} J_{\mathrm{PC}}=172.6 \mathrm{~Hz}, \mathrm{C} 3\right), 63.1(\mathrm{~d}, J=6.7 \mathrm{~Hz}, \mathrm{C}-\mathrm{O}-\mathrm{P}), 63.6(\mathrm{~d}, J=6.7 \mathrm{~Hz}$, C-O-P), $86.6\left(\mathrm{~d},{ }^{3} \mathrm{JPCC}_{\mathrm{PCC}}=9.7 \mathrm{~Hz}, \mathrm{C} 5\right), 115.7(\mathrm{~d}, J=21.5 \mathrm{~Hz}), 118.1(\mathrm{~d}$, $J=12.6 \mathrm{~Hz}), 122.6$ (d, $J=12.9 \mathrm{~Hz}), 124.6$ (d, $J=3.4 \mathrm{~Hz}), 127.7$ (d, $J=3.4 \mathrm{~Hz}), 129.6$ (d, $J=8.6 \mathrm{~Hz}), 141.6\left(\mathrm{~s}, \mathrm{C} 4^{\prime}\right), 159.2(\mathrm{~d}, J=247.9 \mathrm{~Hz}$, $\mathrm{CF}) ;{ }^{31} \mathrm{P}$ NMR $\left(121.5 \mathrm{MHz}, \mathrm{CDCl}_{3}\right) \delta: 21.47 ;{ }^{31} \mathrm{P}$ NMR $(121.5 \mathrm{MHz}$, $\left.\mathrm{C}_{6} \mathrm{D}_{6}\right) \delta$ : 21.79. Anal. Calcd for $\mathrm{C}_{16} \mathrm{H}_{22} \mathrm{FN}_{4} \mathrm{O}_{4} \mathrm{P}: \mathrm{C}, 50.00 ; \mathrm{H}, 5.77 ; \mathrm{N}$, 4.94. Found: C, 49.90; H, 5.84; N, 5.01 .

4.1.2.14. Diethyl 5-(4-(2-fluorophenyl)-1H-1,2,3-triazol-1-yl)-2methylisoxazolidin-3-yl-3-phosphonate 16g. From azidoisoxazolidine 13 (0.153 g, $0.579 \mathrm{mmol})$ and 1-ethynyl-2-fluorobenzene (0.066 mL, $0.579 \mathrm{mmol})$, phosphonate $\mathbf{1 6 g}(0.122 \mathrm{~g}, 98 \%)$ was obtained as a white amorphous solid after purification on silica gel with chloroform-methanol (from 100:1 to 50:1, v/v). M.p.: 97-98 ${ }^{\circ} \mathrm{C}$. IR $\left(\mathrm{KBr}, \mathrm{cm}^{-1}\right) \nu_{\max }: 3482,3092,2983,1620,1590,1479$, $1454,1360,1240,1129,1068,1034,971,864,790 ;{ }^{1} \mathrm{H}$ NMR $\left(300 \mathrm{MHz}, \mathrm{C}_{6} \mathrm{D}_{6}\right) \delta: 0.98\left(\mathrm{t}, 3 \mathrm{H}, J=7.2 \mathrm{~Hz}, \mathrm{POCH}_{2} \mathrm{CH}_{3}\right), 1.05(\mathrm{t}, 3 \mathrm{H}$, $J=7.2 \mathrm{~Hz}, \mathrm{POCH}_{2} \mathrm{CH}_{3}$ ), 2.43 (dddd, $1 \mathrm{H}, J=13.5,9.0,7.8,5.4 \mathrm{~Hz}$, HbC4), 2.58 (dd, $1 \mathrm{H}, J=9.0,9.0,2.4 \mathrm{~Hz}, H C 3$ ), 2.83 (d, $3 \mathrm{H}, J=1.0 \mathrm{~Hz}$, $\mathrm{CH}_{3}-\mathrm{N}$ ), 2.93 (dddd, $1 \mathrm{H}, J=17.2,13.5,9.0,2.1 \mathrm{~Hz}, \mathrm{HaC} 4$ ), 3.80-3.90 $\left(\mathrm{m}, 2 \mathrm{H}, \mathrm{POCH}_{2} \mathrm{CH}_{3}\right), 3.93-4.00\left(\mathrm{~m}, 2 \mathrm{H}, \mathrm{POCH}_{2} \mathrm{CH}_{3}\right), 5.95(\mathrm{dd}, 1 \mathrm{H}$, $J=7.8,2.1 \mathrm{~Hz}, H C 5), 6.80-6.92(\mathrm{~m}, 3 \mathrm{H}), 8.61(\mathrm{~d}, J=3.9 \mathrm{~Hz}, 1 \mathrm{H})$, 8.70-8.65 (m, $1 \mathrm{H}) ;{ }^{13} \mathrm{C}$ NMR $\left(75.5 \mathrm{MHz}, \mathrm{CDCl}_{3}\right) \delta: 16.6$ (d, $J=6.3 \mathrm{~Hz}), 16.7(\mathrm{~d}, J=5.7 \mathrm{~Hz}), 40.7(\mathrm{~d}, J=2.6 \mathrm{~Hz}, \mathrm{C} 4), 45.8$ (s, $\mathrm{CH}_{3}-\mathrm{N}$ ), 62.9 (d, $\left.J=6.7 \mathrm{~Hz}, \mathrm{C}-\mathrm{O}-\mathrm{P}\right), 63.7$ (d, $\left.J=6.8 \mathrm{~Hz}, \mathrm{C}-\mathrm{O}-\mathrm{P}\right)$, $63.8\left(\mathrm{~d},{ }^{1} J_{\mathrm{PC}}=166.9 \mathrm{~Hz}, \mathrm{C} 3\right), 85.6\left(\mathrm{~d},{ }^{3} \mathrm{JPCC}_{\mathrm{PCC}}=9.7 \mathrm{~Hz}, \mathrm{C} 5\right), 115.7(\mathrm{~d}$, $J=21.7 \mathrm{~Hz}), 118.7(\mathrm{~d}, J=13.0 \mathrm{~Hz}), 121.4(\mathrm{~d}, J=13.2 \mathrm{~Hz}), 124.6(\mathrm{~d}$, $J=3.6 \mathrm{~Hz}), 127.9$ (d, $J=3.9 \mathrm{~Hz}), 129.4(\mathrm{~d}, J=8.5 \mathrm{~Hz}), 141.6\left(\mathrm{~s}, \mathrm{C4}^{\prime}\right)$, $159.2(\mathrm{~d}, J=247.6 \mathrm{~Hz}, \mathrm{CF}) ;{ }^{31} \mathrm{P}$ NMR (121.5 MHz, CDCl 3$) \delta: 21.41 ;{ }^{31} \mathrm{P}$ NMR (121.5 MHz, $\left.\mathrm{C}_{6} \mathrm{D}_{6}\right) \delta$ : 21.37. Anal. Calcd for $\mathrm{C}_{16} \mathrm{H}_{22} \mathrm{FN}_{4} \mathrm{O}_{4} \mathrm{P}: \mathrm{C}$, 50.00; H, 5.77; N, 4.94. Found: C, 50.13; H, 6.01; N, 5.12.

4.1.2.15. Diethyl 5-(4-(3-fluorophenyl)-1H-1,2,3-triazol-1-yl)-2methylisoxazolidin-3-yl-3-phosphonate 15h. From azidoisoxazolidine $12(0.103 \mathrm{~g}, 0.390 \mathrm{mmol})$ and 1-ethynyl-3-fluorobenzene (0.045 mL, $0.390 \mathrm{mmol})$, phosphonate $15 \mathrm{~h}(0.122 \mathrm{~g}, 81 \%)$ was obtained as colourless plates after purification on silica gel with chloroform-methanol (from 100:1 to 50:1, v/v). M.p.: 93-95 ${ }^{\circ} \mathrm{C}$. IR $\left(\mathrm{KBr}, \mathrm{cm}^{-1}\right) \nu_{\max }: 3123,2988,1618,1590,1486,1448,1343,1242$, 1052, 1023, 976, 945, 862; ${ }^{1} \mathrm{H}$ NMR (300 MHz, $\left.\mathrm{C}_{6} \mathrm{D}_{6}\right) \delta: 1.02(\mathrm{t}, 3 \mathrm{H}$, $\left.J=6.9 \mathrm{~Hz}, \mathrm{POCH}_{2} \mathrm{CH}_{3}\right) ; 1.09\left(\mathrm{t}, 3 \mathrm{H}, J=6.9 \mathrm{~Hz}, \mathrm{POCH}_{2} \mathrm{CH}_{3}\right), 2.78(\mathrm{~s}$, $3 \mathrm{H}, \mathrm{CH}_{3}-\mathrm{N}$ ), 2.94 (dddd, $\left.1 \mathrm{H}, J=17.7,13.2,10.8,6.9 \mathrm{~Hz}, \mathrm{HbC} 4\right), 3.36$ (dddd, $1 \mathrm{H}, J=13.2,6.9,5.7,1.5 \mathrm{~Hz}, \mathrm{HaC} 4$ ), 3.65 (ddd, $1 \mathrm{H}, J=10.8,6.9$, $2.7 \mathrm{~Hz}, \mathrm{HC} 3), 3.89-4.00\left(\mathrm{~m}, 2 \mathrm{H}, \mathrm{POCH}_{2} \mathrm{CH}_{3}\right), 4.01-4.11(\mathrm{~m}, 2 \mathrm{H}$, $\mathrm{POCH}_{2} \mathrm{CH}_{3}$ ), 5.39 (dd, $\left.1 \mathrm{H}, J=6.9,1.5 \mathrm{~Hz}, \mathrm{HC} 5\right), 6.72-6.80(\mathrm{~m}, 1 \mathrm{H})$, $6.95(\mathrm{~s}, 1 \mathrm{H}), 6.93-7.00(\mathrm{~m}, 1 \mathrm{H}), 7.58(\mathrm{ddd}, 1 \mathrm{H}, J=9.9,2.6,1.6 \mathrm{~Hz})$, $7.67(\mathrm{dt}, 1 \mathrm{H}, J=7.9,1.2 \mathrm{~Hz}) ;{ }^{13} \mathrm{C}$ NMR $\left(75.5 \mathrm{MHz}, \mathrm{CDCl}_{3}\right) \delta: 16.7(\mathrm{~d}$, $J=6.4 \mathrm{~Hz}$ ), 16.8 (d, $J=6.4 \mathrm{~Hz}), 38.8$ (s, C4), 48.3 (d, $J=5.4 \mathrm{~Hz}$, $\left.\mathrm{CH}_{3}-\mathrm{N}\right), 62.9\left(\mathrm{~d},{ }^{1} \mathrm{JC}_{\mathrm{PC}}=172.4 \mathrm{~Hz}, \mathrm{C} 3\right), 63.1(\mathrm{~d}, J=6.9 \mathrm{~Hz}, \mathrm{C}-\mathrm{O}-\mathrm{P})$, $63.6(\mathrm{~d}, J=6.9 \mathrm{~Hz}, \mathrm{C}-\mathrm{O}-\mathrm{P}), 86.7$ (d, $\left.{ }^{3} \mathrm{JPCCC}=10.4 \mathrm{~Hz}, \mathrm{C} 5\right), 112.8$ (d, $J=22.9 \mathrm{~Hz}), 115.3$ (d, $J=21.7 \mathrm{~Hz}), 119.9,121.4$ (d, $J=3.6 \mathrm{~Hz}), 130.5$ $(\mathrm{d}, J=8.5 \mathrm{~Hz}), 132.3(\mathrm{~d}, J=8.7 \mathrm{~Hz}), 147.3,163.1$ (d, $J=245.4 \mathrm{~Hz}, \mathrm{CF})$; ${ }^{31} \mathrm{P}$ NMR (121.5 MHz, CDCl 3 ) $\delta: 21.56 ;{ }^{31} \mathrm{P}$ NMR (121.5 MHz, $\left.\mathrm{C}_{6} \mathrm{D}_{6}\right) \delta$ : 21.75. Anal. Calcd for $\mathrm{C}_{16} \mathrm{H}_{22} \mathrm{FN}_{4} \mathrm{O}_{4} \mathrm{P}$ : C, 50.00; H, 5.77; N, 4.94. Found: C, 50.03; H, 5.60; N, 4.91.

4.1.2.16. Diethyl 5-(4-(3-fluorophenyl)-1H-1,2,3-triazol-1-yl)-2methylisoxazolidin-3-yl-3-phosphonate 16h. From azidoisoxazolidine $13(0.148 \mathrm{~g}, 0.560 \mathrm{mmol})$ and 1-ethynyl-3-fluorobenzene (0.065 mL, $0.560 \mathrm{mmol})$, phosphonate $\mathbf{1 6 h}(0.213 \mathrm{~g}, 98 \%)$ was obtained as a colourless oil after purification on silica gel with chloroform-methanol (from 100:1 to 50:1, v/v). IR (film, $\mathrm{cm}^{-1}$ ) 
$\nu_{\max }: 3470,2980,1619,1589,1478,1454,1440,1359,1240,1044$, 1020, 972, 954, 863; ${ }^{1} \mathrm{H}$ NMR (300 MHz, $\left.\mathrm{C}_{6} \mathrm{D}_{6}\right) \delta: 0.92(\mathrm{t}, 3 \mathrm{H}$, $\left.J=6.9 \mathrm{~Hz}, \mathrm{POCH}_{2} \mathrm{CH}_{3}\right), 0.94\left(\mathrm{t}, 3 \mathrm{H}, J=6.9 \mathrm{~Hz}, \mathrm{POCH}_{2} \mathrm{CH}_{3}\right), 2.39$ (dddd, $1 \mathrm{H}, J=13.5,9.6,7.8,6.0 \mathrm{~Hz}, \mathrm{HbC4}$ ), 2.55 (ddd, $1 \mathrm{H}, J=9.6,8.4$, $1.8 \mathrm{~Hz}, \mathrm{HC} 3$ ), 2.81 (s, $3 \mathrm{H}, \mathrm{CH}_{3}-\mathrm{N}$ ), 2.88 (dddd, $1 \mathrm{H}, J=17.7,13.5,8.4$, $2.1 \mathrm{~Hz}, \mathrm{HaC4}$ ), 3.77-3.87 (m, $\left.4 \mathrm{H}, 2 \times \mathrm{POCH}_{2} \mathrm{CH}_{3}\right), 5.91$ (dd, $1 \mathrm{H}$, $J=7.8,2.1 \mathrm{~Hz}, H C 5), 6.68-6.75(\mathrm{~m}, 1 \mathrm{H}), 6.88-6.95(\mathrm{~m}, 1 \mathrm{H})$, 7.73-7.77 (m, 2H), $8.41(\mathrm{~s}, 1 \mathrm{H}) ;{ }^{13} \mathrm{C}$ NMR $\left(75.5 \mathrm{MHz}, \mathrm{CDCl}_{3}\right) \delta: 16.6$ (d, $J=6.3 \mathrm{~Hz}), 16.7$ (d, $J=6.3 \mathrm{~Hz}), 40.5$ (d, $J=2.4 \mathrm{~Hz}, \mathrm{C} 4), 45.8$ (d, $\left.J=2.5 \mathrm{~Hz}, \mathrm{CH}_{3}-\mathrm{N}\right), 63.1(\mathrm{~d}, J=6.9 \mathrm{~Hz}, \mathrm{C}-\mathrm{O}-\mathrm{P}), 63.4(\mathrm{~d}, J=6.9 \mathrm{~Hz}$, C-O-P), $63.5\left(\mathrm{~d},{ }^{1} J_{\mathrm{PC}}=166.7 \mathrm{~Hz}, \mathrm{C} 3\right), 85.6\left(\mathrm{~d},{ }^{3} J_{\mathrm{PCCC}}=9.2 \mathrm{~Hz}, \mathrm{C} 5\right)$, $112.7(\mathrm{~d}, J=22.7 \mathrm{~Hz}), 115.0 \quad(\mathrm{~d}, J=21.1 \mathrm{~Hz}), 119.0,121.4 \quad(\mathrm{~d}$, $J=3.4 \mathrm{~Hz}), 130.4(\mathrm{~d}, J=8.6 \mathrm{~Hz}), 132.8$ (d, $J=8.0 \mathrm{~Hz}), 146.9$ (d, $J=3.4 \mathrm{~Hz}), 163.1$ (d, $J=245.2 \mathrm{~Hz}, \mathrm{CF}) ;{ }^{31} \mathrm{P}$ NMR $\left(121.5 \mathrm{MHz}, \mathrm{CDCl}_{3}\right)$ $\delta$ : 21.93; ${ }^{31} \mathrm{P}$ NMR $\left(121.5 \mathrm{MHz}, \mathrm{C}_{6} \mathrm{D}_{6}\right) \delta$ : 22.00. Anal. Calcd for $\mathrm{C}_{16} \mathrm{H}_{22} \mathrm{FN}_{4} \mathrm{O}_{4} \mathrm{P}: \mathrm{C}, 50.00 ; \mathrm{H}, 5.77 ; \mathrm{N}, 4.94$. Found: C, 49.87; H, 5.60; $\mathrm{N}$, 4.93 .

4.1.2.17. Diethyl 5-(4-(2,4-difluorophenyl)-1H-1,2,3-triazol-1-yl)-2methylisoxazolidin-3-yl-3-phosphonate 15i. From azidoisoxazolidine $12(0.105 \mathrm{~g}, \quad 0.397 \mathrm{mmol})$ and 1-ethynyl-2,4difluorobenzene $(0.055 \mathrm{~g}, 0.397 \mathrm{mmol})$, phosphonate $15 \mathbf{i}(0.136 \mathrm{~g}$, $85 \%$ ) was obtained as colourless needles after purification on silica gel with chloroform-methanol (20:1, v/v). M.p.: $112-113^{\circ} \mathrm{C}$. IR $\left(\mathrm{KBr}, \mathrm{cm}^{-1}\right) \nu_{\max }: 3435,3140,2984,2924,1621,1561,1495,1444$, 1390, 1336, 1243, 1142, 1065, 1029, 951; ${ }^{1} \mathrm{H}$ NMR (300 MHz, $\left.\mathrm{C}_{6} \mathrm{D}_{6}\right) \delta$ : $1.01\left(\mathrm{t}, 3 \mathrm{H}, J=6.9 \mathrm{~Hz}, \mathrm{POCH}_{2} \mathrm{CH}_{3}\right), 1.07\left(\mathrm{t}, 3 \mathrm{H}, J=6.9 \mathrm{~Hz}, \mathrm{POCH}_{2} \mathrm{CH}_{3}\right)$, $2.80\left(\mathrm{~s}, 3 \mathrm{H}, \mathrm{CH}_{3}-\mathrm{N}\right.$ ), 2.92 (dddd, $1 \mathrm{H}, J=17.7,12.9,10.8,6.9 \mathrm{~Hz}$, HbC4), 3.30 (dddd, $1 \mathrm{H}, J=12.9,6.9,4.5,1.5 \mathrm{~Hz}, \mathrm{HaC} 4$ ), 3.66 (ddd, $1 \mathrm{H}$, $J=10.8,6.9,2.7 \mathrm{~Hz}, \mathrm{HC} 3), 3.90-4.00\left(\mathrm{~m}, 2 \mathrm{H}, \mathrm{POCH}_{2} \mathrm{CH}_{3}\right), 4.03-4.10$ $\left(\mathrm{m}, 2 \mathrm{H}, \mathrm{POCH}_{2} \mathrm{CH}_{3}\right), 5.35$ (dd, $\left.1 \mathrm{H}, J=6.9,1.5 \mathrm{~Hz}, \mathrm{HC} 5\right), 6.49-6.89$ (m, $2 \mathrm{H}), \quad 7.55(\mathrm{dt}, 1 \mathrm{H}, J=3.8 \mathrm{~Hz}), 8.36-8.44(\mathrm{~m}, 1 \mathrm{H}) ;{ }^{13} \mathrm{C} \mathrm{NMR}$ $\left(75.5 \mathrm{MHz}, \mathrm{CDCl}_{3}\right) \delta: 16.7(\mathrm{~d}, J=5.7 \mathrm{~Hz}), 16.8(\mathrm{~d}, J=5.7 \mathrm{~Hz}), 38.9(\mathrm{~s}$, C4), $48.3\left(\mathrm{~d}, J=5.7 \mathrm{~Hz}, \mathrm{CH}_{3}-\mathrm{N}\right), 63.0\left(\mathrm{~d},{ }^{1} \mathrm{JPC}_{\mathrm{PC}}=172.4 \mathrm{~Hz}, \mathrm{C} 3\right), 63.1$ (d, $J=6.9 \mathrm{~Hz}, \quad \mathrm{C}-\mathrm{O}-\mathrm{P}), \quad 63.6 \quad(\mathrm{~d}, \quad J=6.6 \mathrm{~Hz}, \quad \mathrm{C}-\mathrm{O}-\mathrm{P}), 86.7 \quad$ (d, $\left.{ }^{3} J_{\text {PCCC }}=9.7 \mathrm{~Hz}, \mathrm{C} 5\right), 104.3(\mathrm{t}, J=25.4 \mathrm{~Hz}), 112.2(\mathrm{dd}, J=21.7,3.9 \mathrm{~Hz})$, 114.7 (dd, $J=13.6,3.8 \mathrm{~Hz}$ ), 122.1 (d, $J=13.3 \mathrm{~Hz}$ ), 128.8 (dd, $J=9.7$, $5.1 \mathrm{~Hz}$ ), 141.2 (d, $J=4.0 \mathrm{~Hz}$ ), 159.3 (dd, $J=254.4,12.0 \mathrm{~Hz}, \mathrm{CF}), 162.9$ $(\mathrm{dd}, J=254.4,12.5 \mathrm{~Hz}, \mathrm{CF}) ;{ }^{31} \mathrm{P}$ NMR $\left(121.5 \mathrm{MHz}, \mathrm{CDCl}_{3}\right) \delta: 21.45 ;{ }^{31} \mathrm{P}$ NMR (121.5 MHz, $\left.\mathrm{C}_{6} \mathrm{D}_{6}\right) \delta: 21.68$. Anal. Calcd for $\mathrm{C}_{16} \mathrm{H}_{21} \mathrm{~F}_{2} \mathrm{~N}_{4} \mathrm{O}_{4} \mathrm{P}: \mathrm{C}$, 47.76; H, 5.26; N, 13.93. Found: C, 48.00; H, 5.37; N, 13.85 .

4.1.2.18. Diethyl 5-(4-(2,4-difluorophenyl)-1H-1,2,3-triazol-1-yl)-2methylisoxazolidin-3-yl-3-phosphonate 16i. From azidoisoxazolidine $13(0.152 \mathrm{~g}, \quad 0.575 \mathrm{mmol})$ and 1-ethynyl-2,4difluorobenzene $(0.079 \mathrm{~g}, 0.575 \mathrm{mmol})$, phosphonate $16 \mathbf{i}(0.218 \mathrm{~g}$, $94 \%$ ) was obtained as colourless plates after purification on silica gel with chloroform-methanol (20:1, v/v). M.p.: $72-74{ }^{\circ} \mathrm{C}$. IR $(\mathrm{KBr}$, $\mathrm{cm}^{-1}$ ) $\nu_{\text {max }}: 3445,3121,3100,2983,2905,1625,1600,1559,1492$, 1447, 1355, 1257, 1140, 1046, 1025, 967, 946; ${ }^{1} \mathrm{H}$ NMR (300 MHz, $\left.\mathrm{CDCl}_{3}\right) \delta: 1.32(\mathrm{t}, 3 \mathrm{H}, J=6.9 \mathrm{~Hz}), 1.36(\mathrm{t}, 3 \mathrm{H}, J=6.9 \mathrm{~Hz}), 3.00(\mathrm{~s}, 3 \mathrm{H})$, $3.00-3.21(\mathrm{~m}, 2 \mathrm{H}), 3.25-3.40(\mathrm{~m}, 1 \mathrm{H}), 4.12-4.30(\mathrm{~m}, 4 \mathrm{H}), 6.46(\mathrm{dd}$, $1 \mathrm{H}, J=7.8,2.4 \mathrm{~Hz}), 6.85-6.95(\mathrm{~m}, 1 \mathrm{H}), 6.96-7.03(\mathrm{~m}, 1 \mathrm{H}), 8.28(\mathrm{dt}$, $1 \mathrm{H}, J=8.7,6.3 \mathrm{~Hz}), 8.44(\mathrm{~d}, 1 \mathrm{H}, J=3.6 \mathrm{~Hz}) ;{ }^{13} \mathrm{C}$ NMR $(75.5 \mathrm{MHz}$, $\left.\mathrm{CDCl}_{3}\right) \delta: 16.4(\mathrm{~d}, J=5.5 \mathrm{~Hz}), 40.3,45.6,62.7(\mathrm{~d}, J=6.6 \mathrm{~Hz}, \mathrm{C}-\mathrm{O}-\mathrm{P})$, $63.4(\mathrm{~d}, J=6.6 \mathrm{~Hz}, \mathrm{C}-\mathrm{O}-\mathrm{P}), 63.5\left(\mathrm{~d},{ }^{1} J_{\mathrm{PC}}=166.0 \mathrm{~Hz}, \mathrm{C} 3\right), 85.4(\mathrm{~d}$, ${ }^{3} J$ PCCC $\left.=9.1 \mathrm{~Hz}, \mathrm{C} 5\right), 104.0(\mathrm{t}, J=25.8 \mathrm{~Hz}), 111.7(\mathrm{dd}, J=21.2,3.4 \mathrm{~Hz})$, 115.0 (dd, $J=13.5,4.0 \mathrm{~Hz}), 120.8(\mathrm{~d}, J=12.0 \mathrm{~Hz}), 128.6$ (dd, $J=11.5$, $5.2 \mathrm{~Hz}$ ), 140.6, 158.9 (dd, $J=238.5,13.1 \mathrm{~Hz}, \mathrm{CF}$ ), 162.2 (dd, $J=242.2$, $12.7 \mathrm{~Hz}, \mathrm{CF}) ;{ }^{31} \mathrm{P}$ NMR (121.5 MHz, $\left.\mathrm{CDCl}_{3}\right) \delta: 20.75$. Anal. Calcd for $\mathrm{C}_{16} \mathrm{H}_{21} \mathrm{~F}_{2} \mathrm{~N}_{4} \mathrm{O}_{4} \mathrm{P}: \mathrm{C}, 47.76 ; \mathrm{H}, 5.26 ; \mathrm{N}, 13.93$. Found: C, 47.67; H, 5.06; $\mathrm{N}, 13.99$.

4.1.2.19. Diethyl 2-methyl-5-(4-(pyridin-2-yl)-1H-1,2,3-triazol-1-yl) isoxazolidin-3-yl-3-phosphonate 15j. From azidoisoxazolidine 12
$(0.152 \mathrm{~g}, \quad 0.575 \mathrm{mmol})$ and 2-ethynylpyridine $\quad(0.058 \mathrm{~mL}$, $0.575 \mathrm{mmol})$, phosphonate $\mathbf{1 5 j}(0.160 \mathrm{~g}, 76 \%)$ was obtained as a colourless oil after purification on silica gel with chloroform-methanol (100:1, v/v). IR (film, $\mathrm{cm}^{-1}$ ) $\nu_{\max }$ : 3466, 3138, 2983, 2930, 1603, 1572, 1474, 1424, 1343, 1254, 12,110, 1160, 1050, 1025, 972, 788; ${ }^{1} \mathrm{H}$ NMR $\left(300 \mathrm{MHz}, \mathrm{C}_{6} \mathrm{D}_{6}\right) \delta: 0.99(\mathrm{t}, 3 \mathrm{H}, J=6.9 \mathrm{~Hz}$, $\left.\mathrm{POCH}_{2} \mathrm{CH}_{3}\right), 1.06\left(\mathrm{t}, 3 \mathrm{H}, \mathrm{J}=6.9 \mathrm{~Hz}, \mathrm{POCH}_{2} \mathrm{CH}_{3}\right), 2.76\left(\mathrm{~s}, 3 \mathrm{H}, \mathrm{CH}_{3}-\mathrm{N}\right)$, 2.85 (dddd, $1 \mathrm{H}, J=17.7,12.9,11.1,6.9 \mathrm{~Hz}, \mathrm{HbC}$ ), 3.22 (dddd, $1 \mathrm{H}$ $J=12.9,6.9,4.5,1.2 \mathrm{~Hz}, \mathrm{HaC} 4$ ), 3.58 (ddd, $1 \mathrm{H}, J=10.5,6.6,1.8 \mathrm{~Hz}$, $\mathrm{HC} 3), 3.86-3.99\left(\mathrm{~m}, 2 \mathrm{H}, \mathrm{POCH}_{2} \mathrm{CH}_{3}\right), 4.00-4.08\left(\mathrm{~m}, 2 \mathrm{H}, \mathrm{POCH}_{2} \mathrm{CH}_{3}\right)$, $5.39(\mathrm{~d}, 1 \mathrm{H}, J=6.9,1.2 \mathrm{~Hz}, \mathrm{HC} 5), 6.59-6.64(\mathrm{~m}, 1 \mathrm{H}), 7.09-7.16(\mathrm{~m}$, $1 \mathrm{H}), 8.18(\mathrm{~s}, 1 \mathrm{H}), 8.36(\mathrm{~d}, 1 \mathrm{H}, J=7.9 \mathrm{~Hz}), 8.44-8.47(\mathrm{~m}, 1 \mathrm{H}) ;{ }^{13} \mathrm{C} \mathrm{NMR}$ $\left(75.5 \mathrm{MHz}, \mathrm{CDCl}_{3}\right) \delta: 16.5(\mathrm{~d}, J=6.2 \mathrm{~Hz}), 16.6(\mathrm{~d}, J=5.8 \mathrm{~Hz}), 38.9(\mathrm{~d}$, $J=2.4 \mathrm{~Hz}, \mathrm{C} 4), 48.0\left(\mathrm{~d}, J=6.0 \mathrm{~Hz}, \mathrm{CH}_{3}-\mathrm{N}\right), 62.6\left(\mathrm{~d},{ }^{1} \mathrm{JPC}=172.4 \mathrm{~Hz}\right.$, C3), 62.9 (d, $J=7.2 \mathrm{~Hz}, \mathrm{C}-\mathrm{O}-\mathrm{P}), 63.4(\mathrm{~d}, J=6.9 \mathrm{~Hz}, \mathrm{C}-\mathrm{O}-\mathrm{P}), 86.5$ (d, $\left.{ }^{3} J_{\text {PCCC }}=10.5 \mathrm{~Hz}, \mathrm{C} 5\right), 120.2,121.7,123.0,136.9,148.7,149.2,149.5$; ${ }^{31} \mathrm{P}$ NMR (121.5 MHz, $\mathrm{CDCl}_{3}$ ) $\delta: 21.44 ;{ }^{31} \mathrm{P}$ NMR (121.5 MHz, $\left.\mathrm{C}_{6} \mathrm{D}_{6}\right) \delta$ : 21.62. Anal. Calcd for $\mathrm{C}_{15} \mathrm{H}_{22} \mathrm{~N}_{5} \mathrm{O}_{4} \mathrm{P}$ : C, 49.04; $\mathrm{H}, 6.04 ; \mathrm{N}, 19.07$. Found: C, 48.97; H, 5.95; N, 19.19.

4.1.2.20. Diethyl 2-methyl-5-(4-(pyridin-2-yl)-1H-1,2,3-triazol-1-yl) isoxazolidin-3-yl-3-phosphonate 16j. From azidoisoxazolidine 13 $(0.156 \mathrm{~g}, \quad 0.590 \mathrm{mmol})$ and 1-ethynylpyridine $(0.060 \mathrm{~g}$, $0.590 \mathrm{mmol})$, phosphonate $\mathbf{1 6 j}(0.188 \mathrm{~g}, 87 \%)$ was obtained as white amorphous solid after purification on silica gel with chloroform-methanol (from 50:1 to 20:1, v/v). M.p.: $108-109{ }^{\circ} \mathrm{C}$. IR $\left(\mathrm{KBr}, \mathrm{cm}^{-1}\right) \nu_{\max }: 3447,3113,2983,2906,1595,1446,1358,1252$, 1167, 1041, 969, 804; ${ }^{1} \mathrm{H}$ NMR (300 MHz, $\left.\mathrm{CDCl}_{3}\right) \delta: 1.31(\mathrm{t}, 3 \mathrm{H}$, $J=7.2 \mathrm{~Hz}), 1.33(\mathrm{t}, 3 \mathrm{H}, J=7.2 \mathrm{~Hz}), 2.99(\mathrm{~s}, 3 \mathrm{H}), 3.00-3.22(\mathrm{~m}, 2 \mathrm{H})$, $3.24-3.40(\mathrm{~m}, 1 \mathrm{H}), 4.10-4.25(\mathrm{~m}, 4 \mathrm{H}), 6.43(\mathrm{dd}, J=6.9,1.8 \mathrm{~Hz}, 1 \mathrm{H})$, 7.20-7.25 (m, 1H), 7.75-7.82 (m, $1 \mathrm{H}), 8.17(\mathrm{~d}, J=8.1 \mathrm{~Hz}, 1 \mathrm{H})$, 8.57-8.60 (m, 1H), $8.70(\mathrm{~s}, 1 \mathrm{H}) ;{ }^{13} \mathrm{C} \mathrm{NMR}\left(75.5 \mathrm{MHz} \mathrm{CDCl}_{3}\right) \delta: 16.4$ $(\mathrm{d}, J=6.3 \mathrm{~Hz}), 16.5$ (d, $J=6.0 \mathrm{~Hz}), 40.6$ (d, $J=2.3 \mathrm{~Hz}, \mathrm{C} 4), 45.6$ (s, $\mathrm{CH}_{3}-\mathrm{N}$ ), 62.7 (d, J=6.9 Hz, C-O-P), 63.6 (d, $J=6.3 \mathrm{~Hz}, \mathrm{C}-\mathrm{O}-\mathrm{P}$ ), $63.6\left(\mathrm{~d},{ }_{\mathrm{PPC}}^{1}=166.0 \mathrm{~Hz}, \mathrm{C} 3\right), 85.4\left(\mathrm{~d},{ }^{3} J_{\mathrm{PCCC}}=9.2 \mathrm{~Hz}, \mathrm{C} 5\right), 120.1,120.9$, 122.8, 136.7, 148.4, 149.3, 150.1; ${ }^{31} \mathrm{P}$ NMR $\left(121.5 \mathrm{MHz}, \mathrm{CDCl}_{3}\right) \delta$ : 21.19. Anal. Calcd for $\mathrm{C}_{15} \mathrm{H}_{22} \mathrm{~N}_{5} \mathrm{O}_{4} \mathrm{P}$ : C, 49.04; $\mathrm{H}, 6.04 ; \mathrm{N}, 19.07$. Found: C, 49.05; H, 5.90; N, 19.01.

4.1.2.21. Diethyl 2-methyl-5-(4-(1-methyl-1H-imidazol-5-yl)-1H1,2,3-triazol-1-yl)isoxazolidin-3-yl-3-phosphonate 15k. From azidoisoxazolidine $12(0.151 \mathrm{~g}, 0.571 \mathrm{mmol})$ and 5-ethynyl-1-methyl$1 \mathrm{H}$-imidazole $(0.058 \mathrm{~mL}, 0.571 \mathrm{mmol})$, phosphonate 15k $(0.128 \mathrm{~g}$, $61 \%$ ) was obtained as a colourless oil after purification on silica gel with chloroform-methanol (from 50:1 to 20:1, v/v). IR (film, $\mathrm{cm}^{-1}$ ) $\nu_{\text {max }}$ : 3113, 2980, 1692, 1613, 1555, 1444, 1239, 1160, 1037, 1020, 967; ${ }^{1} \mathrm{H}$ NMR (300 MHz, $\left.\mathrm{C}_{6} \mathrm{D}_{6}\right) \delta: 1.02\left(\mathrm{t}, 3 \mathrm{H}, J=7.1 \mathrm{~Hz}, \mathrm{POCH}_{2} \mathrm{CH}_{3}\right), 1.08$ (t, 3H, $\left.J=7.1 \mathrm{~Hz}, \mathrm{POCH}_{2} \mathrm{CH}_{3}\right), 2.80\left(\mathrm{~s}, 3 \mathrm{H}, \mathrm{CH}_{3}-\mathrm{N}\right), 2.94$ (dddd, $1 \mathrm{H}$, $J=17.4,13.2,10.8,6.9 \mathrm{~Hz}, \mathrm{HbC} 4$ ), 3.28 (dddd, $1 \mathrm{H}, J=13.2,6.9,5.1$, $1.8 \mathrm{~Hz}, \mathrm{HaC} 4), 3.29$ (s, $3 \mathrm{H}, \mathrm{CH}_{3}-\mathrm{N}$ ), 3.66 (ddd, $1 \mathrm{H}, J=10.8,6.9$, $2.7 \mathrm{~Hz}, \mathrm{HC} 3), 3.91-3.99\left(\mathrm{~m}, 2 \mathrm{H}, \mathrm{POCH}_{2} \mathrm{CH}_{3}\right), 3.99-4.10(\mathrm{~m}, 2 \mathrm{H}$, $\mathrm{POCH}_{2} \mathrm{CH}_{3}$ ), 5.47 (dd, $\left.1 \mathrm{H}, J=6.9,1.8 \mathrm{~Hz}, \mathrm{HC} 5\right), 6.97(\mathrm{~s}, 1 \mathrm{H}), 7.08$ (s, $1 \mathrm{H}), 7.44(\mathrm{~s}, 1 \mathrm{H}) ;{ }^{13} \mathrm{C} \mathrm{NMR}\left(75.5 \mathrm{MHz}, \mathrm{CDCl}_{3}\right) \delta: 16.6(\mathrm{~d}, J=6.4 \mathrm{~Hz})$, $16.7\left(\mathrm{~d}, J=6.3 \mathrm{~Hz}\right.$ ), 33.8, 38.8 (s, C4), $48.1\left(\mathrm{~d}, J=5.4 \mathrm{~Hz}, \mathrm{CH}_{3}-\mathrm{N}\right)$, $62.8\left(\mathrm{~d},{ }^{1} J_{\mathrm{PC}}=172.1 \mathrm{~Hz}, \mathrm{C} 3\right), 63.0(\mathrm{~d}, J=6.8 \mathrm{~Hz}, \mathrm{C}-\mathrm{O}-\mathrm{P}), 63.5(\mathrm{~d}$, $J=6.6 \mathrm{~Hz}, \mathrm{C}-\mathrm{O}-\mathrm{P}), 86.5\left(\mathrm{~d},{ }^{3} J_{\mathrm{PCCC}}=10.0 \mathrm{~Hz}, \mathrm{C} 5\right), 120.9,122.9,128.5$, 138.9, 139.5; ${ }^{31} \mathrm{P}$ NMR $\left(121.5 \mathrm{MHz}, \mathrm{CDCl}_{3}\right) \delta: 21.41 ;{ }^{31} \mathrm{P} \mathrm{NMR}$ (121.5 MHz, $\left.\mathrm{C}_{6} \mathrm{D}_{6}\right) \delta: 21.68$. Anal. Calcd for $\mathrm{C}_{14} \mathrm{H}_{23} \mathrm{~N}_{6} \mathrm{O}_{4} \mathrm{P}: \mathrm{C}, 45.40 ; \mathrm{H}$, 6.26; N, 22.69. Found: C, 45.45; H, 6.09; N, 22.50.

4.1.2.22. Diethyl 2-methyl-5-(4-(1-methyl-1H-imidazol-5-yl)-1H1,2,3-triazol-1-yl)isoxazolidin-3-yl-3-phosphonate 16k. From azidoisoxazolidine $13(0.135 \mathrm{~g}, 0.511 \mathrm{mmol})$ and 5-ethynyl-1-methyl$1 H$-imidazole $(0.052 \mathrm{~mL}, 0.511 \mathrm{mmol})$, phosphonate 16k $(0.122 \mathrm{~g}$, $65 \%$ ) was obtained as a colourless oil after purification on silica gel 
with chloroform-methanol (from 50:1 to 20:1, v/v). IR (film, $\mathrm{cm}^{-1}$ ) $\nu_{\max }: 3110,2982,1612,1502,1442,1240,1161,1114,1045,1020,975$; ${ }^{1} \mathrm{H}$ NMR $\left(300 \mathrm{MHz}, \mathrm{CDCl}_{3}\right) \delta: 1.32(\mathrm{t}, 3 \mathrm{H}, J=7.1 \mathrm{~Hz}), 1.36(\mathrm{t}, 3 \mathrm{H}$, $J=7.1 \mathrm{~Hz}), 2.99(\mathrm{~d}, 3 \mathrm{H}, J=1.0 \mathrm{~Hz}), 3.00-3.20(\mathrm{~m}, 2 \mathrm{H}), 3.20-3.40(\mathrm{~m}$, $1 \mathrm{H}), 3.93(\mathrm{~s}, 3 \mathrm{H}), 4.10-4.25(\mathrm{~m}, 2 \mathrm{H}), 6.45(\mathrm{dd}, J=7.8,2.1 \mathrm{~Hz}, 1 \mathrm{H})$, $7.54(\mathrm{~s}, 1 \mathrm{H}), 8.30(\mathrm{~s}, 1 \mathrm{H}) ;{ }^{13} \mathrm{C}$ NMR $\left(75.5 \mathrm{MHz}, \mathrm{CDCl}_{3}\right) \delta: 16.4(\mathrm{~d}$, $J=6.2 \mathrm{~Hz}), 33.5,40.4(\mathrm{~d}, J=2.2 \mathrm{~Hz}, \mathrm{C} 4), 45.6\left(\mathrm{~d}, J=2.0 \mathrm{~Hz}, \mathrm{CH}_{3}-\mathrm{N}\right)$, 62.8 (d, $J=7.0 \mathrm{~Hz}, \mathrm{C}-\mathrm{O}-\mathrm{P}), 63.2$ (d, $J=6.9 \mathrm{~Hz}, \mathrm{C}-\mathrm{O}-\mathrm{P}), 63.5$ (d, $\left.{ }^{1} J_{\mathrm{PC}}=166.8 \mathrm{~Hz}, \mathrm{C} 3\right), 85.5\left(\mathrm{~d},{ }^{3} J_{\mathrm{PCCC}}=9.5 \mathrm{~Hz}, \mathrm{C} 5\right), 119.8,123.5,128.7$, 138.8, 139.4; ${ }^{31} \mathrm{P}$ NMR (121.5 MHz, $\left.\mathrm{CDCl}_{3}\right) \delta: 20.97$. Anal. Calcd for $\mathrm{C}_{14} \mathrm{H}_{23} \mathrm{~N}_{6} \mathrm{O}_{4} \mathrm{P}: \mathrm{C}, 45.40 ; \mathrm{H}, 6.26 ; \mathrm{N}, 22.69$. Found: $\mathrm{C}, 45.30 ; \mathrm{H}, 6.21 ; \mathrm{N}$, 22.80 .

\subsection{Antiviral activity assays}

The antiviral assays [except anti-human immunodeficiency virus (HIV) assays] were based on inhibition of virus-induced cytopathicity in HEL [herpes simplex virus type 1 (HSV-1), HSV-2 $(G)$, vaccinia virus and vesicular stomatitis virus], Vero (parainfluenza-3, reovirus-1, Sindbis, Coxsackie B4, and Punta Toro virus), HeLa (vesicular stomatitis virus, Coxsackie virus B4, and respiratory syncytial virus), MDCK (influenza A (H1N1 and H3N1) and influenza B virus) or CrFK (feline herpes virus; feline corona virus (FIPV)) cell cultures. Confluent cell cultures in microtiter 96well plates were inoculated with 100 cell culture inhibitory dose$50\left(\mathrm{CCID}_{50}\right)$ of virus $\left(1 \mathrm{CCID}_{50}\right.$ being the virus dose to infect $50 \%$ of the cell cultures) in the presence of varying concentrations (250, $50,10, \ldots \mu \mathrm{M})$ of the test compounds. Viral cytopathicity was recorded as soon as it reached completion in the control virusinfected cell cultures that were not treated with the test compounds. The methodology of the anti-HIV assays was as follows: human CEM $\left(\sim 3 \times 10^{5}\right.$ cells $\left./ \mathrm{cm}^{3}\right)$ cells were infected with $100 \mathrm{CCID}_{50}$ of HIV-1(III $)$ or HIV-2(ROD)/mL and seeded in $200 \mu \mathrm{L}$ wells of a microtiter plate containing appropriate dilutions of the test compounds. After 4 days of incubation at $37^{\circ} \mathrm{C}$, HIV-induced CEM giant cell formation was examined microscopically.

\subsection{Cytostatic activity assays}

Murine leukaemia L1210, human T-lymphocyte CEM, human cervix carcinoma (HeLa) and human lung fibroblast (HEL) cells were suspended at $300,000-500,000$ cells/mL of culture medium, and $100 \mu \mathrm{L}$ of a cell suspension was added to $100 \mu \mathrm{L}$ of an appropriate dilution of the test compounds in wells of 96-well microtiter plates. After incubation at $37^{\circ} \mathrm{C}$ for two (L1210) or three (CEM, HeLa, HEL) days, the cell number was determined using a Coulter counter. The $\mathrm{IC}_{50}$ was defined as the compound concentration required to inhibit cell proliferation by $50 \%$.

\section{Acknowledgements}

The preliminary experiments in this project were conducted by Miss Zuzanna Pawłowska, M.Sc. The synthetic part of this work was supported by Medical University of Łódź internal found (503-30141 ). The virological part of this work was supported by the K. U. Leuven (GOA no. 10/14). We thank Mrs. Leentje Persoons, Mrs. Frieda De Meyer, Mrs. Lies Van den Heurck, Mrs. Anita Camps, Mr. Steven Carmans, Mrs. Leen Ingels and Mrs. Lizette van Berckelaer for excellent technical assistance.

\section{References}

[1] V. Calderone, F.L. Fiamingo, G. Amato, I. Giorgi, O. Livi, A. Martelli, E. Martinotti, 1,2,3-Triazol-carboxanilides and 1,2,3-triazol-( $N$-benzyl)- carboxamides as BK-potassium channel activators. XII, Eur. J. Med. Chem. 43 (2008) 2618-2626.

[2] E.-M. Kim, M.-H. Joung, C.-M. Lee, H.-J. Jeong, S.T. Lim, M.-H. Sohn, D.W. Kim, Synthesis of Tc-99m labeled 1,2,3-triazole-4-yl c-met binding peptide as a potential c-met receptor kinase positive tumor imaging agent, Bioorg. Med. Chem. Lett. 20 (2010) 4240-4243.

[3] M.J. Giffin, H. Heaslet, A. Brik, Y.-C. Lin, G. Cauvi, C-H. Wong, D.E. McRee, J.H. Elder, C.D. Stout, B.E. Torbett, A copper(I)-catalyzed 1,2,3-triazole azidealkyne click compound is a potent inhibitor of a multidrug-resistant HIV-1 protease variant, J. Med. Chem. 51 (2008) 6263-6270.

[4] Q. Wang, S. Chittaboina, H.N. Barnhill, Highlights in organic chemistry advances in 1,3-dipolar cycloaddition reaction of azides and alkynes a prototype of "click" chemistry, Lett. Org. Chem. 2 (2005) 293-301.

[5] L. Zhou, A. Amer, M. Korn, R. Burda, J. Balzarini, E. De Clercq, E.R. Kern, P.F. Torrence, Synthesis and antiviral activities of 1,2,3-triazole functionalized thymidines: 1,3-dipolar cycloaddition for efficient regioselective diversity generation, Antivir. Chem. Chemother. 16 (2005) 375-383.

[6] P.M. Chaudhary, S.R. Chavan, F. Shirazi, M. Razdan, P. Nimkar, S.P. Maybhate, A.P. Likhite, R. Gonnade, B.G. Hazara, M.V. Deshpande, S.R. Deshpande, Exploration of click reaction for the synthesis of modified nucleosides as chitin synthase inhibitors, Bioorg. Med. Chem. 17 (2009) 2433-2440.

[7] J.-L. Yu, Q.-W. Wu, Q.-S. Zhang, X.-D. Xi, N. N-Liu, Y.-Z. Li, Y.-H. Liu, H.-Q. Yin, Synthesis and antitumor activity of novel $2^{\prime}, 3^{\prime}$-diethanethio- $2^{\prime}, 3^{\prime}, 5^{\prime}$-trideoxy5'-triazolonucleoside analogues, Eur. J. Med. Chem. 45 (2010) 3219-3222.

[8] S.M. Park, H. Yang, S.-K. Park, H.M. Kim, B.H. Kim, Design, synthesis, and anticancer activities of novel perfluoroalkyltriazole-appended 2'-deoxyuridines, Bioorg. Med. Chem. Lett. 20 (2010) 5831-5834.

[9] Y.-S. Lee, S.M. Park, H.M. Kim, S.-K. Park, K. Lee, C.W. Lee, B.H. Kim, C5Modified nucleosides exhibiting anticancer activity, Bioorg. Med. Chem. Lett. 19 (2009) 4688-4691.

[10] W.E. Lindsell, C. Murray, P.N. Preston, T.A.J. Woodman, Synthesis of 1,3-diynes in the purine, pyrimidine, 1,3,5-triazine and acridine series, Tetrahedron 56 (2000) 1233-1245.

[11] H.B. Lazrek, M. Taourirte, T. Oulih, J.L. Barascut, J.L. Imbach, C. Pannecouque, M. Witvrouw, E. De Clercq, Synthesis and anti-HIV activity of new modified 1,2,3-triazole acyclonucleosides, Nucleosides Nucleotides Nucleic Acids 20 (2001) 1949-1960.

[12] H. Elayadi, M. Smietana, C. Pannecouque, P. Leyssen, J. Neyts, J.-J. Vasseur, H.B. Lazrek, Straightforward synthesis of triazoloacyclonucleotide phosphonates as potential HCV inhibitors, Bioorg. Med. Chem. Lett. 20 (2010) 7365-7368.

[13] P. Chittepu, V.R. Sirivolu, F. Seela, Nucleosides and oligonucleotides containing 1,2,3-triazole residues with nucleobase tethers: synthesis via the azide-alkyne 'click' reaction, Bioorg. Med. Chem. 16 (2008) 8427-8439.

[14] D.G. Piotrowska, $N$-Substituted $C$-diethoxyphosphorylated nitrones as useful synthons for the synthesis of $\alpha$-aminophosphonates, Tetrahedron Lett. 47 (2006) 5363-5366.

[15] D.G. Piotrowska, Stereochemistry of cycloaddition of (S)-N-(1-phenylethyl)-Cdiethoxyphosphorylated nitrone with vinyl acetate. Studies on mutarotation of 3-(0,O-diethylphosphoryl)-5-hydroxyisoxazolidines, Tetrahedron: Asymmetry 19 (2008) 279-287.

[16] A. Piperno, S.V.Giofrè, D. Iannazzo, R. Romeo, G. Romeo, U. Chiacchio, A. Rescifina, D.G. Piotrowska, Synthesis of C-4'truncated phosphonated carbocyclic $2^{\prime}$-oxa- $3^{\prime}$ azanucleosides as antiviral agents, J. Org. Chem. 75 (2010) 2798-2805.

[17] K. Slámová, P. Marhol, K. Bezouška, L. Lindkvist, S.G. Hansen, V. Křen, H.H. Jensen, Synthesis and biological activity of glycosyl-1H-1,2,3-triazoles, Bioorg. Med. Chem. Lett. 20 (2010) 4263-4265.

[18] S. Dedola, D.L. Hughes, S.A. Nepogodiev, M. Rejzek, R.A. Field, Synthesis of $\alpha-$ and $\beta$-D-glucopyranosyl triazoles by CuAAC 'click chemistry': reactant tolerance, reaction rate, product structure and glucosidase inhibitory properties, Carbohydr. Res. 345 (2010) 1123-1134.

[19] K. El Akri, K. Bougrin, J. Balzarini, A. Farajd, R. Benhida, Efficient synthesis and in vitro cytostatic activity of 4-substituted triazolyl-nucleosides, Bioorg. Med. Chem. Lett. 17 (2007) 6656-6659.

[20] R. Kumar, P. Tiwari, P.R. Maulik, A.K. Misra, A generalized procedure for the one-pot preparation of glycosyl azides and thioglycosides directly from unprotected reducing sugars under phase-transfer reaction conditions, Eur. J. Org. Chem. (2006) 74-79.

[21] D.G. Piotrowska, Stereochemistry of substituted isoxazolidines derived from $\mathrm{N}$-methyl C-diethoxyphosphorylated nitrone, Tetrahedron 62 (2006) 12306-12317.

[22] C. Loukou, M. Tosin, H. Müller-Bunz, P.V. Murphy, Synthesis of sugar-lactams from azides of glucuronic acid, Carbohydr. Res. 342 (2007) 1953-1959.

[23] J.-R. Neeser, J.M.J. Tronchet, E.J. Charollais, Structural analysis of 3-C-phosphonates, -phosphinates, and -phosphine oxides of branched-chain sugars, Can. J. Chem. 61 (1983) 2112-2120.

[24] G. Adiwidjaja, B. Meyer, J. Thiem, Darstellung und Kristallstruktur von endo-2Dimethylphosphono-exo-2-hydroxy-(-)-camphan zur Bestimmung von ${ }_{3}^{3} J(C C C P)-V i c i n a l k o p p l u n g e n, Z$. Naturforsch. 34b (1979) 1547-1551.

[25] V.V. Rostovtsev, L.G. Green, V.V. Fokin, K.B. Sharpless, A stepwise Huisgen cycloaddition process: copper(I)-catalyzed regioselective "ligation" of azides and terminal alkynes, Angew. Chem. Int. Ed. 41 (2002) 2596-2599.

[26] H.C. Kolb, M.G. Finn, K.B. Sharpless, Click chemistry: diverse chemical function from a few good reactions, Angew. Chem. Int. Ed. 40 (2001) 2004-2021.

[27] E.T. Kool, H.O. Sintim, The difluorotoluene debate - a decade later, Chem. Commun. (2006) 3665-3675. 